NIST GCR 18-019

\title{
Mechanical properties and off-gassing characteristics of new and legacy SCBA facepieces
}

\author{
Richard M. Kesler \\ Constandinos Mitsingas \\ Adam G. Quiat \\ Tonghun Lee \\ Daniel Madrzykowski \\ Gavin P. Horn \\ Illinois Fire Service Institute Research \\ University of Illinois
}

This publication is available free of charge from:

https://doi.org/10.6028/NIST.GCR.18-019

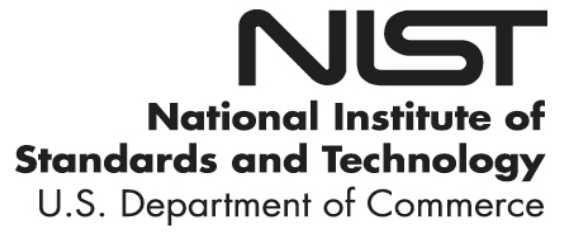


NIST GCR 18-019

\section{Mechanical properties and off-gassing characteristics of new and legacy SCBA facepieces}

Prepared for

U.S. Department of Commerce

Engineering Laboratory

National Institute of Standards and Technology

Gaithersburg, MD 20899

Richard M. Kesler Constandinos Mitsingas

Adam G. Quiat

Tonghun Lee

Daniel Madrzykowski

Gavin P. Horn

Illinois Fire Service Institute Research

University of Illinois

This publication is available free of charge from:

https://doi.org/10.6028/NIST.GCR.18-019

December 2018

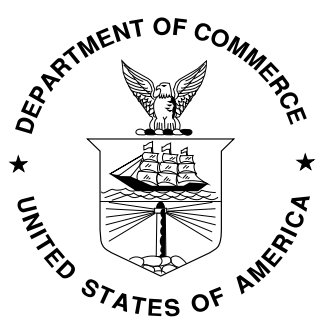

U.S. Department of Commerce Wilbur L. Ross, Jr., Secretary

National Institute of Standards and Technology Walter Copan, NIST Director and Undersecretary of Commerce for Standards and Technology 


\section{Disclaimer}

This publication was produced as part of contract 60NANB15D359 with the National Institute of Standards and Technology. The contents of this publication do not necessarily reflect the views or policies of the National Institute of Standards and Technology or the US Government. 

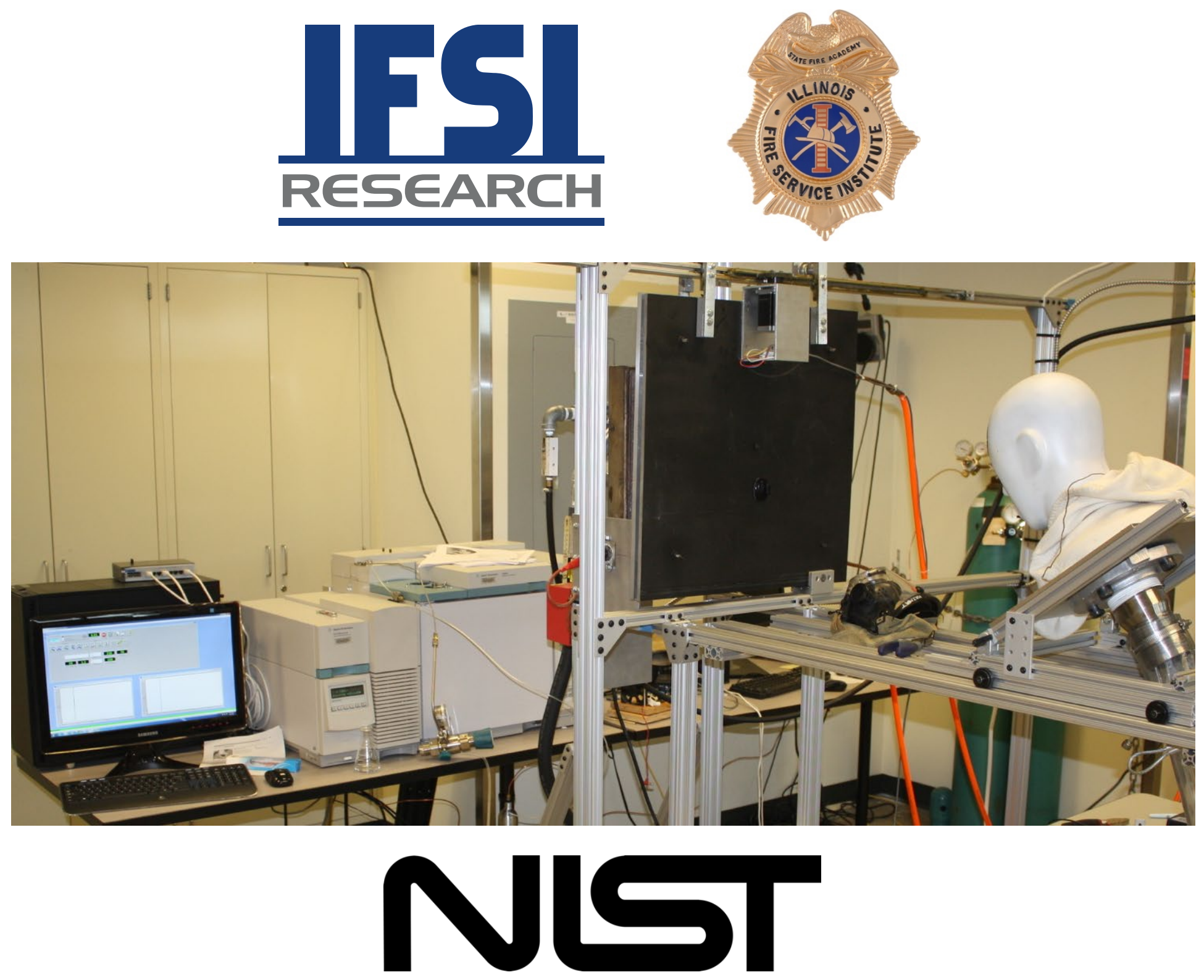

Mechanical properties and off-gassing characteristics of new and legacy SCBA facepieces

Richard M. Kesler, Constandinos Mitsingas, Adam G. Quait Tonghun Lee, Daniel Madrzykowski, Gavin P. Horn 



\begin{abstract}
In today's structure fires, evolving fire loads and higher heat release rates mean that fires grow larger and faster than ever before. Firefighting personal protective equipment (PPE) can be subjected to these severe thermal conditions repeatedly during firefighting operations. The self-contained breathing apparatus (SCBA) is a critical component of PPE that isolates the firefighter from hot and potentially toxic gases and particulate, present as byproducts of combustion. In recent years, changes in NFPA standards have resulted in the introduction of new SCBA facepiece designs and materials. However, the facepiece lens is still often considered the "weak-link" of the firefighting ensemble.

SCBA facepiece lenses from two editions of the NFPA 1981 standard around which significant new tests were introduced were exposed to repeated thermal loads similar to those that could be encountered on a fireground $\left(5 \mathrm{~kW} / \mathrm{m}^{2}\right.$ for 5 minutes for 100 cycles, and $10 \mathrm{~kW} / \mathrm{m}^{2}$ for 1.5 minutes for 10 cycles). Samples from subsets of these SCBA were subjected to quasistatic tensile tests and dynamic impact testing and compared to samples from new, unexposed facepieces. Identical facepiece samples were subjected to the NFPA 1981 Lens Radiant Heat Test that was introduced in the 2013 version of the standard, which drove much of the change in facepiece design. Finally, facepiece lenses were tested for potential off-gassing that was proposed to be the result of polycarbonate decomposition from typical fireground thermal loads, due to the concern that these gasses could be inhaled by the firefighter wearing the SCBA facepiece.

Statistically significant differences were found between facepieces certified to different versions of NFPA 1981. Those lenses certified to the 2013 edition had higher tensile strength and absorbed more energy but were more brittle than the 2007 edition materials. Exposure to repeated thermal loads resulted in changes to the tensile strength, strain to failure, maximal load, and energy absorbed, but the magnitude and direction of change was dependent on the thermal exposure and lens model. However, regardless of model and previous thermal exposure, all facepieces were able to maintain positive pressure after being exposed to the 5 minutes at $15 \mathrm{~kW} / \mathrm{m}^{2}$ that is included in the Lens Radiant Heat Test.

Off-gas testing from the SCBA facepiece lenses showed no measurable polymers being released under typical and extreme fireground conditions using the GC-MS technique employed. Chemically dissolving the lens material confirmed that bisphenol A was a primary component of the polycarbonate along with important polymer chain terminators, and trace amounts of other polymers used in scratch resistant and thermal coatings.
\end{abstract}

\title{
Key words
}

Facepiece; firefighting; SCBA. 


\section{Table of Contents}

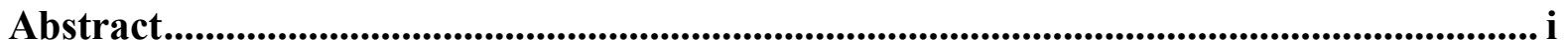

Introduction \& Background ...................................................................................... 1

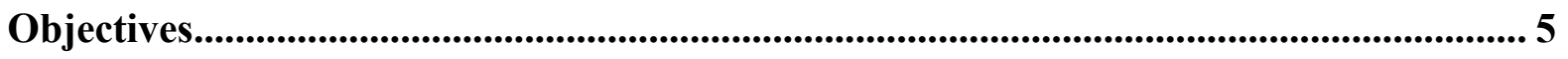

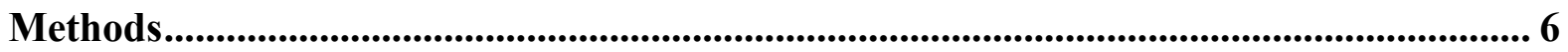

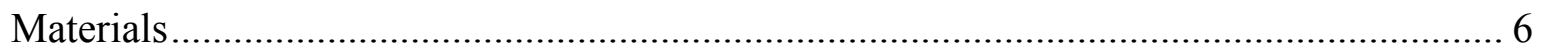

Testing Apparatus and Exposures ..................................................................... 7

Radiant Panel Apparatus ................................................................................ 7

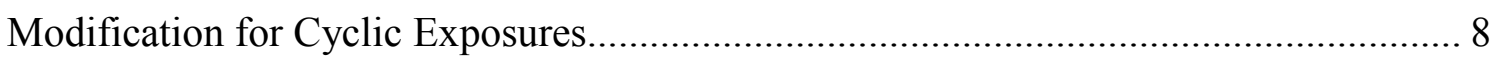

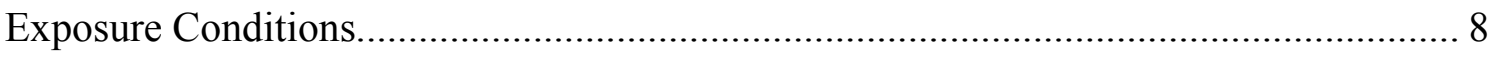

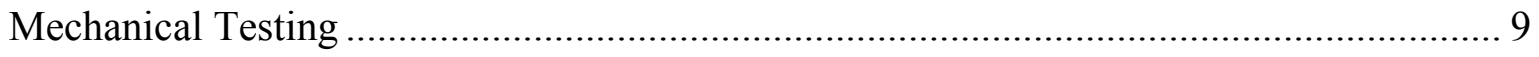

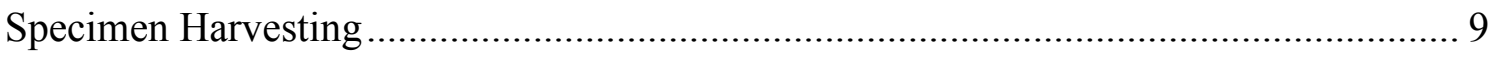

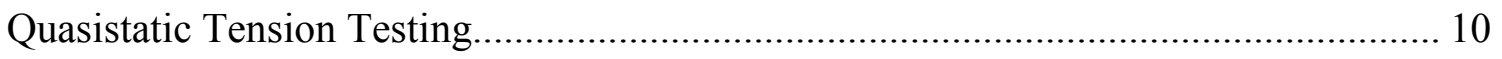

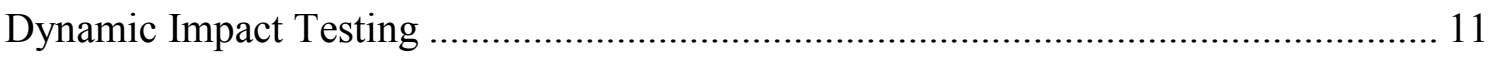

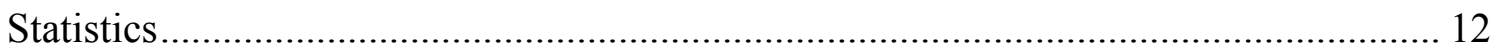

Thermal Testing - NFPA 1981 Lens Radiant Heat Testing .......................................... 12

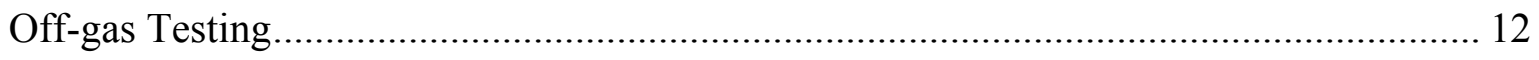

Gas Chromatograph with Mass Spectrometer apparatus.......................................... 13

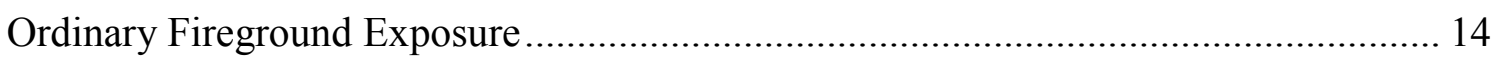

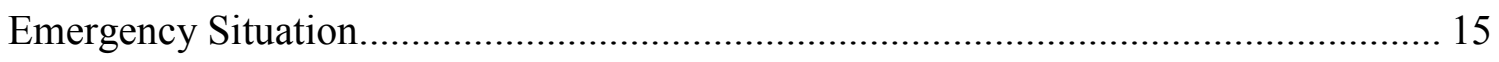

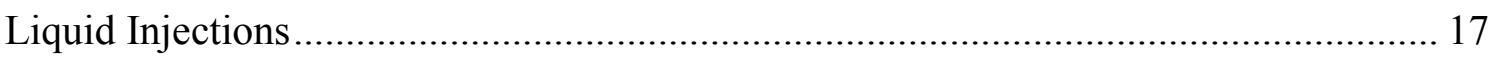

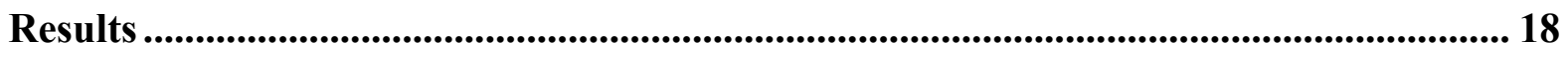

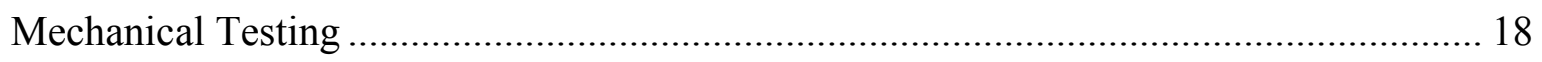

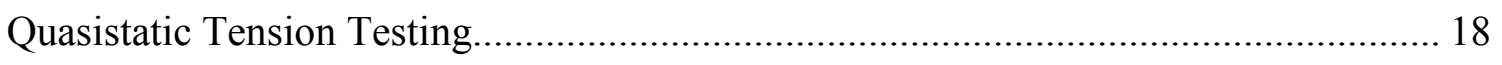

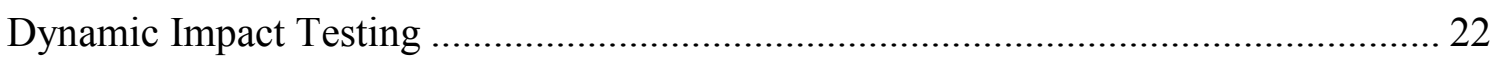

NFPA 1981 Lens Radiant Heat Testing ................................................................. 24

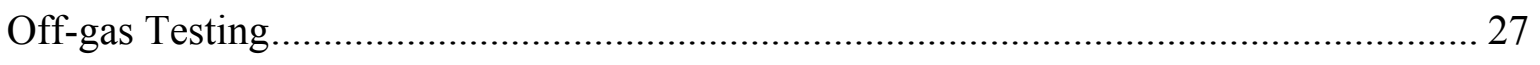

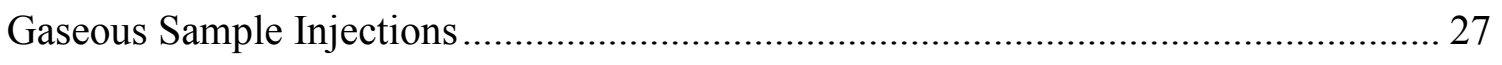

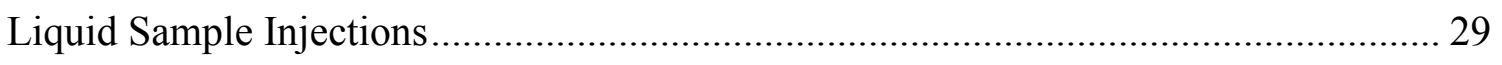

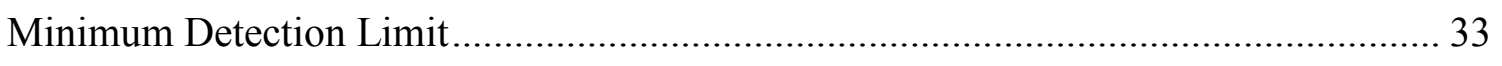

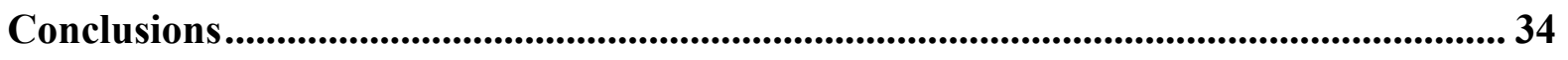

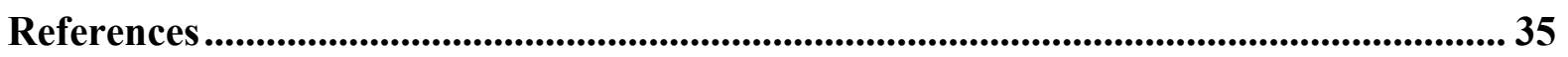




\section{Introduction \& Background}

The environment in which firefighters operate has changed dramatically over the last several decades. The introduction and advancements of synthetic materials throughout the home, office and commercial occupancies have altered the fuels commonly found in today's buildings, and changes in design and architecture have impacted fire behavior within structures. As a result of typically higher heat release rates, the fire service is responding to faster fire development and spread and more intense thermal conditions. Over the same time period, advances have been made in the design, materials, and manufacturing of firefighters' personal protective equipment (PPE). The increased protection that modern firefighting PPE provides allows firefighters to work in environments that would otherwise not be survivable. Thus, there exists a real need to address emerging PPE issues. Both the 2011 and 2015 editions of the National Fire Service Research Agenda identify the need to address PPE related health and safety issues [1,2].

Firefighters commonly perform fireground operations in conditions that are immediately dangerous to life and health (IDLH). Respiratory protection in the IDLH environment is typically achieved through the use of a self-contained breathing apparatus (SCBA). The SCBA consists of a compressed air tank worn on the back that provides a positive pressure air supply to the facepiece. The SCBA facepiece and positive pressure air supply isolates the firefighter's face, eyes and airway from hazardous and irritating smoke and gases. However, the thermal stability of common facepiece lens materials are typically lower than that of the other PPE elements, resulting in some to label the facepiece as a "weak link" in the firefighting ensemble $[3,4]$. If the integrity of the facepiece is compromised, exposure to the toxic, irritant and high temperature products of combustion can potentially incapacitate a firefighter and - in some cases - provide a lethal exposure. A number of NIOSH firefighter fatality reports have suggested that the thermal performance of the SCBA lenses was not capable of withstanding the ambient conditions that were encountered in those specific instances, thus being identified as a contributing factor in fire fighter line-of-duty fatalities in both training and fire response [5-11]. Additionally, the National Fire Fighter Near Miss Reporting System includes multiple events of reported thermal damage to SCBA facepieces [12-15].

Traditionally, polycarbonate has been used for firefighting SCBA facepiece lens applications due to its optical clarity, impact resistance, and thermal resistance. The principal reactant in the preparation of polycarbonate is the monomer Bisphenol-A (4,4' -isopropylidene diphenol), commonly known as BPA. Previous studies have shown that the BPA monomer can be released from polycarbonate when heated to $120^{\circ} \mathrm{C}-125^{\circ} \mathrm{C}$ for more than 30 minutes [16]. The health effects of BPA at low environmental exposures are not completely understood, though research has suggested negative impacts [17-20].

The glass transition temperature of polycarbonate as reported in the literature is approximately $150{ }^{\circ} \mathrm{C}$ [21]. At higher temperatures, polycarbonate facepieces may begin to lose structural integrity and the lens can begin to deform under its own weight or in combination with 
the positive pressure conditions maintained within the SCBA. As has been documented in some of the reports above, holes may begin to form in the facepiece under severe conditions. Melting temperatures can vary widely depending on the type of polycarbonate used, between $215{ }^{\circ} \mathrm{C}$ and $338^{\circ} \mathrm{C}[21,22]$. However, it is not clear if BPA could off-gas from firefighting facepiece lenses that can negatively impact firefighters breathing from their SCBA under realistic fireground conditions.

These thermal properties result in two levels of risk to the firefighter. At relatively low temperatures $\left(120^{\circ} \mathrm{C}-125^{\circ} \mathrm{C}\right)$ there is a risk of thermal breakdown of the polycarbonate, which some have suggested may result in release within the SCBA facepiece. Exposure to non-lethal doses of products of polymer decomposition may lead to reduced cognitive function [23] and several line-of-duty death reports include disorientation and confusion of the firefighter [8, 24, 25]. It is unclear if potential exposure to degradation of the facepiece materials could contribute to the confusion and disorientation of firefighters in extreme thermal situations. Presently, relevant studies examining the effects of off-gassing and therefore chemical exposure to firefighters from the polycarbonate facepiece are lacking.

At higher temperatures there is a risk of physical failure of the facepiece and disruption of the isolation between the firefighter and the IDLH environment. The damage experienced by the SCBA facepiece recovered from some of the fatal incidents described above suggest that temperatures in excess of the melting point were experienced at some point during the events. However, it is not always clear if the initial facepiece failure was due to a purely thermal exposure or some combination of thermal exposure and mechanical stresses. It is also unclear if prior exposures may have weakened the facepiece by lowering thermal and/or mechanical protective properties.

The National Institute of Standards and Technology (NIST) and Fire Protection Research Foundation (FPRF) convened a workshop in 2010 to discuss research needs in order to reduce the occurrence of heat related respirator failures during firefighting. One of the key performance needs identified at the workshop was to reassess the current test methods. To support this need, these groups highlighted research priorities, including the need to both define the fire environment and conduct representative and realistic testing. Defining typical conditions for representative testing is challenging as these conditions are highly variable, depending on fuel type and quantity, ventilation opening size and timing, and structure design, construction and interior finish among others. Donnelly et al. [26] proposed a classification of firefighting environments specifically for electronic equipment, based on the existing literature at the time. The four categories include specific maximum time limits for given temperature and heat flux conditions (Table 1). It is expected that firefighters' equipment, including PPE, may be exposed to Thermal Classes I and II on a fairly regular basis during normal interior fireground operations and in some cases during exterior operations where a high heat flux may be encountered from large fires or vent plumes. Class III is proposed as an upper limit for normal, but short term, fireground operations, while Class IV exposures are severe, emergency conditions to which firefighter equipment would not be 
typically exposed, but may be encountered in rapidly deteriorating situations. Madrzykowski [27] compiled the data from Donnelly [26] and Utech [28] with literature on thermal conditions and potential firefighter equipment exposures during test burns, providing an excellent overview of typical conditions in which firefighters operate (Figure 1).

Table 1. Recommendations for firefighter thermal classes adapted from Donnelly et al. [26]

\begin{tabular}{|c|c|c|c|}
\hline Thermal Class & $\begin{array}{c}\text { Maximum } \\
\text { Time }(\mathbf{m i n})\end{array}$ & $\begin{array}{c}\text { Maximum } \\
\text { Temperature }\left({ }^{\circ} \mathbf{C}\right)\end{array}$ & $\begin{array}{c}\text { Maximum } \\
\text { Heat Flux }\left(\mathrm{kW} / \mathrm{m}^{2}\right)\end{array}$ \\
\hline I & 25 & 100 & 1 \\
\hline II & 15 & 160 & 2 \\
\hline III & 2 & 260 & 10 \\
\hline IV & $<1$ & $>260$ & $>10$ \\
\hline
\end{tabular}
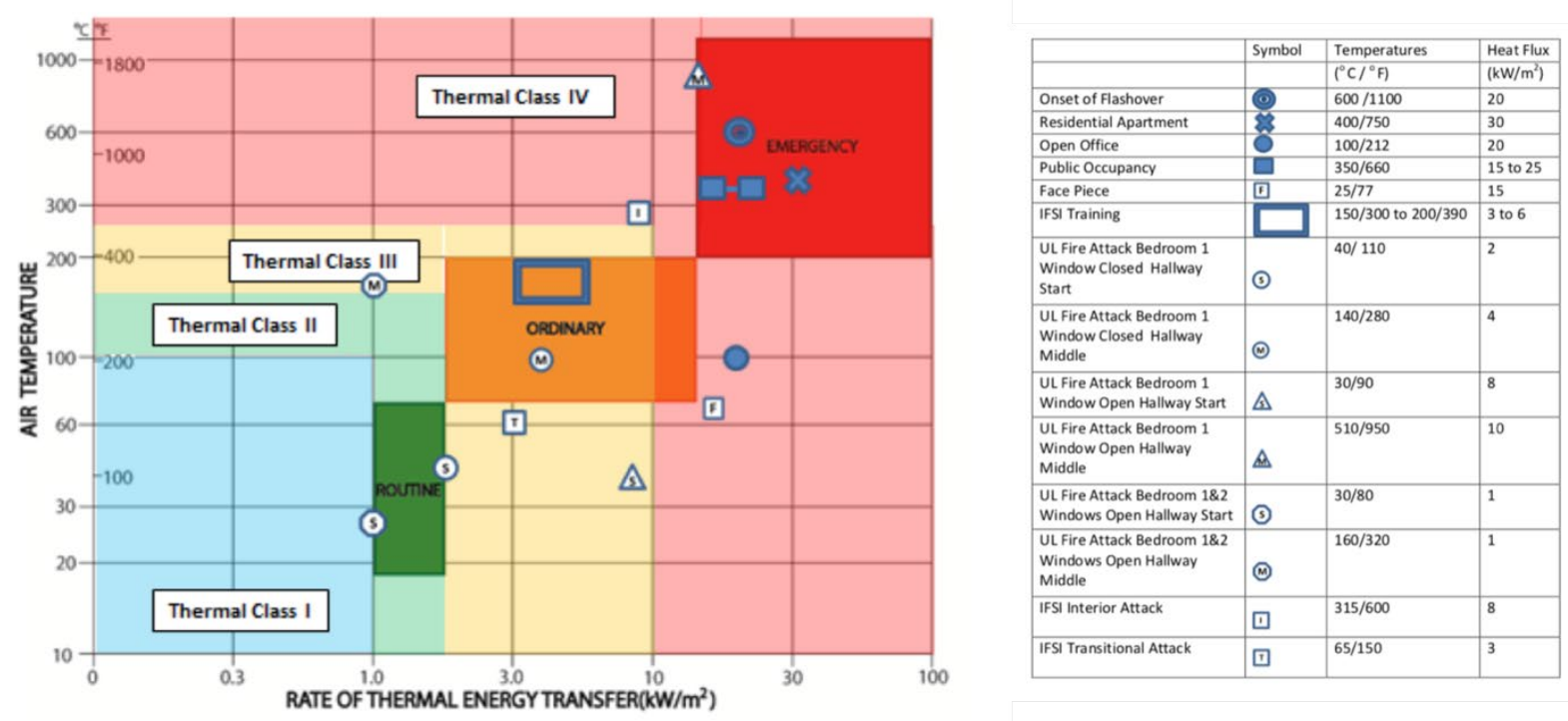

Figure 1. Visual representation of potential thermal conditions during fireground operations, from Madrzykowski [27].

To carefully study these facepiece failures, NIST developed a laboratory based radiant exposure test for SCBA facepieces [29] that was later incorporated in to the 2013 version of NFPA's 1981 standard, as the "Lens Radiant Heat Test". This new test subjects the SCBA facepieces to a radiant heat flux of $15 \mathrm{~kW} / \mathrm{m}^{2}$ for five minutes. As part of this test, the facepiece is required to maintain a positive-pressure air supply inside the facepiece for a total of 24 minutes. In addition, the 2013 version contains an "Elevated Temperature Heat and Flame Resistance Test" that exposes the SCBA to $260{ }^{\circ} \mathrm{C}$ for five minutes in a convection oven. This test is followed by 10 seconds of direct flame contact. These exposures represent the most aggressive Class III 
environment and a Class IV exposure. As a result of this update to the NFPA 1981 standard, most SCBA manufacturers made considerable changes to their SCBA facepieces, including modifying the materials, coatings and/or thickness of the facepiece lenses in order to address the concerns with thermal stability.

However, while the new standard tests subject the SCBA to more severe environments, NIST researchers also found that some SCBA facepieces experienced surface "cracking" at heat fluxes as low as $7 \mathrm{~kW} / \mathrm{m}^{2}$ and bubble formation at fluxes as low as $5 \mathrm{~kW} / \mathrm{m}^{2}$ [29]. While this type of damage would most likely result in a firefighter replacing their lens, it is not clear what risks to performance are encountered if not replaced or how the damage evolution changes in the facepieces produced in the 2013 version of the NFPA 1981 standard. An NFPA bulletin released in 2012 recommended that any SCBA facepiece lens found to have cracks, crazing, bubbling, deformation, discoloring, gaps or holes should be immediately removed from service and a replacement issued [4]. Thus, visible evidence of exposure to intense heat is suggested as an indication of thermal degradation and potential failure. While this recommendation is logical, there does not appear to be any scientific evidence that lack of such indications of prior exposure are sufficient to suggest that physical property degradation has not occurred. In their conclusions Putorti et al. [29] suggested that "Although much was learned about conditions associated with thermal degradation of SCBA facepiece lenses, more research and development are needed to understand the thermal degradation of facepiece lenses".

As a follow-on to this initial laboratory study, NIST funded the University of Illinois Fire Service Institute (IFSI) to study "typical" exposures to which an SCBA facepiece might experience - potentially hundreds of times in its service life - yet may leave no indication of damage or minimal bubbling and crazing that may not be easily detected [30]. It is likely that the facepiece is commonly exposed to Class I through low intensity Class III environments fairly regularly and may show minimal or no indications of thermal damage as a result. Results from that study indicated that samples collected from field worn SCBA facepieces had similar elastic properties and ultimate strength values compared to new, unused facepiece materials, but that a significant reduction in ductility was detected in the field worn samples (Table 2).

The field worn lenses included those with damage ranging from minimal to obvious microcracking, though results do not suggest that the increased visual indications of damage were related to more severe changes in mechanical properties. By comparison, samples tested in the laboratory after repeated exposure to Class I and II heat fluxes did not have a measurable effect on mechanical properties, even after 100 exposures to maximal Class II conditions. For slightly higher Class III heat fluxes $\left(5 \mathrm{~kW} / \mathrm{m}^{2}\right)$ substantial reductions in ductility were noted after 100 cycles. Samples from these $5 \mathrm{~kW} / \mathrm{m}^{2}$ - 100 cycle samples performed similar to field worn samples, though with less severe reductions in strain to failure. It was also noted that there did not appear to be a one-to-one correlation between visual indications of thermal damage and impacts on mechanical properties. That study utilized SCBA facepieces that were produced prior to the 2013 updates to NFPA 1981 
due in part to the delay in implementing the new standard and lack of field exposed samples for comparison.

Table 2. Summary of initial results from IFSI/NIST SCBA study focusing on mechanical strength properties of new facepieces as compared to field worn lenses [30].

\begin{tabular}{|c|c|c|c|}
\hline \multirow{2}{*}{ Sample } & $\begin{array}{c}\text { Modulus of } \\
\text { Elasticity (GPa) }\end{array}$ & $\begin{array}{c}\text { Tensile Strength } \\
(\mathrm{MPa})\end{array}$ & $\begin{array}{c}\text { Strain to Failure } \\
(-/-)\end{array}$ \\
\hline New Lenses & $2.20 \pm .05$ & $66.1 \pm 1.0$ & $1.32 \pm .11$ \\
\hline Field Worn Lenses & $2.15 \pm .08$ & $70.2 \pm 1.2$ & $0.24 \pm .11$ \\
\hline
\end{tabular}

\section{Objectives}

The objectives of this study were to quantify the changes in properties for facepieces compliant with the 2013 edition of NFPA 1981 compared to pre-2013 NFPA 1981 compliant SCBA. The study focused on differences in both brand-new samples and samples exposed to repeated Class III thermal exposures. Specifically, the following three properties were tested:

(1) Mechanical performance (strength, stiffness, ductility) of the facepieces including standardized quasistatic and dynamic property tests

(2) Thermal performance of the facepieces following NFPA 1981 Lens Radiant Heat Test protocol

(3) The potential for chemical exposures to firefighters from SCBA facepiece off-gassing during thermal exposure. 


\section{Methods}

\section{Materials}

SCBA facepieces were tested from both NFPA 1981 - 2007 edition and NFPA 1981 - 2013 edition models, are outlined in Table 3. The first facepiece, 1-07A, is an older geometry model of a facepiece meeting the standards of the 2007 edition of NFPA 1981. The second facepiece, 1-07B, is an updated geometry model of a facepiece meeting the standards of NFPA 1981-2007 edition, while the third facepiece 1-13, meets the standards of NFPA 1981-2013 edition and is very similar in geometry to 1-07B, which allows more straightforward comparison than other SCBA manufacturers that made substantial changes to SCBA facepiece design for the updated standard. Samples of facepieces from a second manufacturer that meets the 2007 and 2013 editions of NFPA 1981, were also included in off-gassing testing, though results were largely similar to the other manufacture, so this report will focus on the complete data set from manufacture \#1 . Commercially available polycarbonate sheet was used in the off-gassing tests to serve as a baseline material.

Table 3. SCBA facepieces used during this project.

\begin{tabular}{|c|c|}
\hline $\begin{array}{c}\text { SCBA Facepiece } \\
\text { (Mfg-NFPA Ed) }\end{array}$ & Description \\
\hline 1-07A & Meets NFPA 1981-2007 edition, older geometry \\
\hline 1-07B & Meets NFPA 1981-2007 edition, updated geometry \\
\hline 1-13 & Meets NFPA 1981-2013 edition \\
\hline PS & Polycarbonate Sheet (Off-gas tests only) \\
\hline
\end{tabular}

Historically, the most common material used in SCBA facepieces has been polycarbonate, and the main monomer is 4,4'-(propane-2,2-diyl)diphenol or more commonly known as Bisphenol A (BPA). Even though polycarbonate performs well under impact, it is relatively soft and subject to mechanical damage due to surface scratches. To reduce scratching in polycarbonate safety glasses, manufacturers use various scratch-resistant and antireflection coatings [31]. While specific compounds are generally kept as trade secrets by manufacturers some common materials for antireflection coatings are magnesium fluoride, silicon nitride, silicon oxide, titanium dioxide and silicon dioxide. For abrasion resistance and inertness to hostile environmental conditions, polysiloxane may be used, as well as primarily monomeric, dimerized silanes, silane hydrozylates, and siliceous material. Hard silicone coatings may also be useful as anti-fog, UV absorbing, chemical resistant, and/or tinted coatings. These are some of the compounds hypothesized to be observed during the tests, and were specifically targeted, though testing was conducted to survey for the largest range of possible off-gassing compounds with the available equipment. 


\section{Testing Apparatus and Exposures}

\section{$\underline{\text { Radiant Panel Apparatus }}$}

Thermal exposures were achieved by altering the radiant panel apparatus developed by NIST [29] and utilized in the NFPA 1981 "Lens Radiant Heat Test" [32] for facepiece testing (Figure 2). The panel provides controlled and repeatable radiant heat flux to the SCBA facepiece while minimizing the convective heat transfer. Natural gas was utilized in accordance with ASTM E162-09 Standard Test Method for Surface Flammability of Materials Using a Radiant Energy Source. The air flow rate to the panel for the $5 \mathrm{~kW} / \mathrm{m}^{2}$ exposures was approximately $450 \mathrm{~L} / \mathrm{min}$ (960 SCFH), and the natural gas flow rate was approximately $33 \mathrm{~L} / \mathrm{min}(70 \mathrm{SCFH})$ and adjusted to ensure a uniform blue sheet flame at the surface of the panel. Panel exhaust was removed from the testing environment through the building's laboratory ventilation system. The radiant panel was allowed to heat up and stabilize thermal conditions for one hour prior to testing. Before each scenario, a Schmidt-Boelter heat flux gauge mounted on a translating cart was placed on the frame in front of the radiant heat flux panel to determine the location at which the facepiece placed on the headform would experience the appropriate heat flux. Heat flux was measured at the beginning of each test day and spot checked at the end of various testing days to ensure consistency of exposure.

A headform was then placed at the indicated location so the front of the SCBA lens received the prescribed incident heat flux and was parallel to the radiant panel surface (Figure 2). Simulated breathing was achieved using a Honeywell Posi 3 USB PosiChek system, with a breathing rate of $40 \mathrm{~L} / \mathrm{min}$ as outlined in NFPA 1981 [32]. The PosiChek was connected to the headform assembly via a $51 \mathrm{~mm}$ inner diameter tube such that the PosiChek system was not exposed to radiant heat. Air was provided to the headform via an SCBA connected to a high-pressure line supplied by a six-tank compressed air cascade to allow for extended test periods throughout a given day.
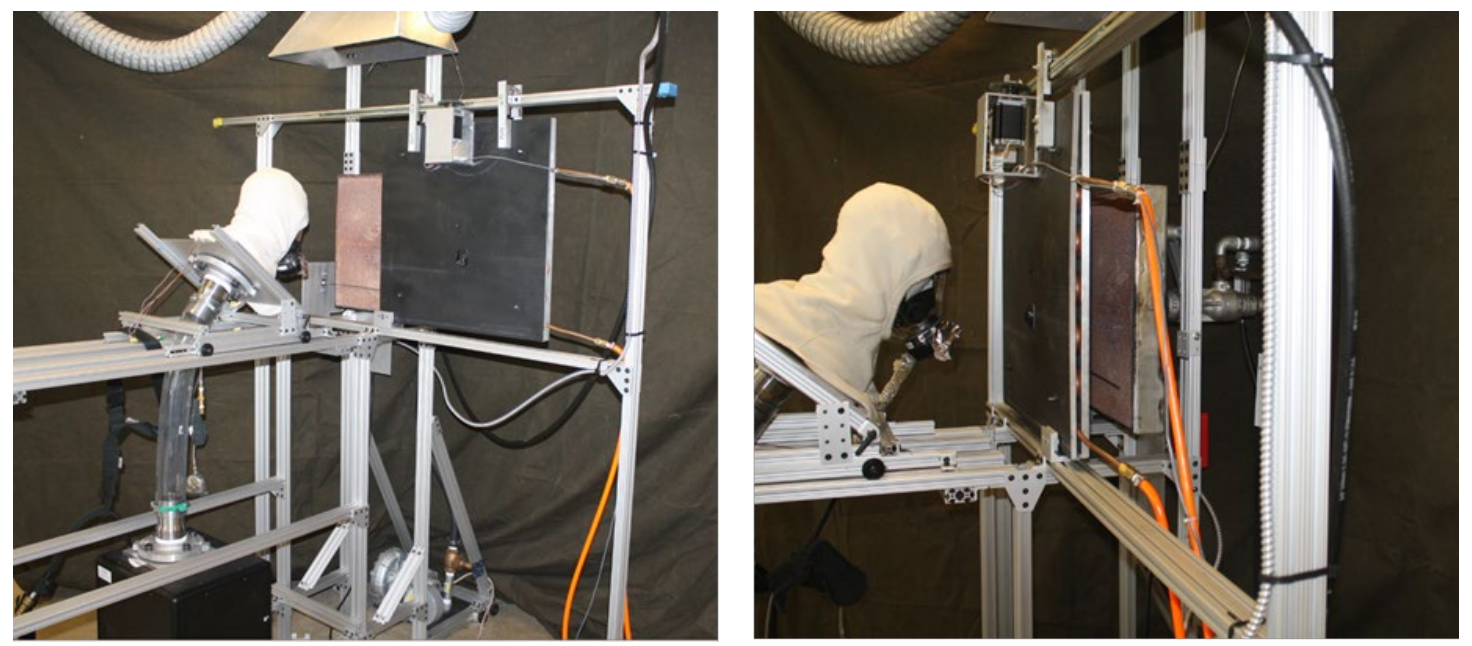

Figure 2. Radiant Panel Test Apparatus modified for repeated exposure testing [30]. 
Modification for Cyclic Exposures

To achieve repeatable and reliable cyclic heat flux exposures, the NIST test apparatus was modified by IFSI such that an automated, translating thermal shield was installed between the radiant panel and the SCBA facepiece as reported in NIST GCR 17-014 [30]. The water-cooled radiant heat shield was mounted on a track system with a programmable microcontroller motor on a rack-and-pin drive train. While the heat shield was engaged, heat produced by the radiant panel was blocked from reaching the SCBA facepiece. Cooling of the panel is achieved by water flowing through a circuitous copper pipe to prevent re-radiating heat to the test sample while the shield is engaged. A pre-programmed duty cycle was uploaded to the microcontroller to ensure consistent timing for exposure and shielding such that the facepiece returns to room temperature prior to the next exposure. Further information on the design, construction and implementation of the shield and frame, shield translation, and system concept can be found in the report on the IFSI study on repeated SCBA facepiece exposures to radiant heat [30].

\section{Exposure Conditions}

In the previous IFSI study (NIST GCR 17-014) [30], it was found that 1 and $2 \mathrm{~kW} / \mathrm{m}^{2}$ heat flux exposures resulted in no accumulation of visual damage in the lens or impact on mechanical properties, but $5 \mathrm{~kW} / \mathrm{m}^{2}$ for 5 minutes over 100 cycles resulted in statistically significant changes in mechanical properties. Therefore, samples in this study were exposed to 100 cycles at a heat flux of $5 \mathrm{~kW} / \mathrm{m}^{2}$. The duty cycle consisted of 5 minutes exposed and 25 minutes behind the radiant shield in room air, breathing compressed dried air throughout the duration of the duty cycle. A new exposure protocol was instituted for this series of tests to study short duration exposure to high intensity Class III conditions. As such, facepieces were exposed to 10 cycles at a heat flux of $10 \mathrm{~kW} / \mathrm{m}^{2}$ (maximal Class III heat flux), with a duty cycle of 90 seconds exposed followed by 5 minutes shielded. To provide a comparison with baseline properties, facepieces were also tested in the unexposed, new condition (Table 4).

Table 4: Experiment Exposure Conditions

\begin{tabular}{|c|c|c|c|c|}
\hline $\begin{array}{c}\text { Heat Flux } \\
\left(\mathrm{kW} / \mathrm{m}^{2}\right)\end{array}$ & $\begin{array}{c}\text { Duration of } \\
\text { Exposure }(\mathrm{min})\end{array}$ & $\begin{array}{c}\text { Duration of } \\
\text { Cooling }(\mathrm{min})\end{array}$ & $\begin{array}{c}\text { Number of } \\
\text { Cycles }\end{array}$ & Identifier \\
\hline $\mathbf{0}$ & 0 & 0 & 0 & $0-0-0$ \\
\hline $\mathbf{5}$ & 5 & 25 & 100 & $5-5-100$ \\
\hline 10 & 1.5 & 5 & 10 & $10-1.5-10$ \\
\hline
\end{tabular}




\section{Mechanical Testing}

Specimen Harvesting

SCBA facepiece geometry limits the opportunity for preparing test specimens from the lenses to specific geometry. Due to the curvature of the lenses special care was required to avoid damaging the lenses during sample preparation that might alter mechanical properties beyond the thermal damage from the radiant exposures. To conduct ASTM standard mechanical property evaluations, two types of samples were prepared: tensile dogbone test strips and square impact testing coupons (Figure 3). Facepieces designated for tension testing were cut into 5 rectangular strips spanning the front of the facepiece using a band saw (Figure 3a). After the rectangular strips were rough cut from the facepiece the test strip was then milled to the final dogbone shape (Figure 4). A rotary mill and mill guide were used to produce ASTM D638-10 Type IV dogbone-type specimens [33]. A mill guide assembly drawing and supporting engineering drawings can be found in the appendix of NIST GCR 17-014 [30]. Final dimensions were measured from each sample using digital calipers. Facepiece curvature and design led to slightly varying thicknesses across the facepiece locations.

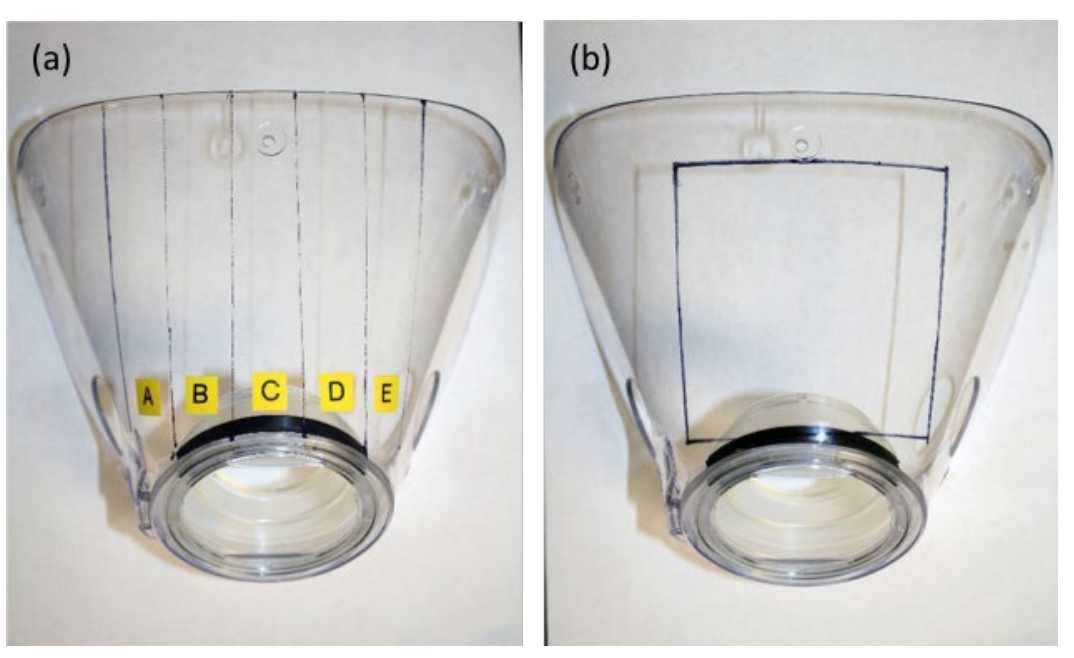

Figure 3. Mechanical test sample harvesting locations: (a) Tensile Test, and (b) Impact Test.

ASTM D7137 [34] square (89x89mm) impact testing samples were rough cut from the center of the facepiece (Figure $3 b$ ). Burrs on the specimen edges were filed smooth so that the specimen would lay flat when clamped during impact testing (Figure 4). Thickness measurements were collected from all edges of the impact test specimens and an average value was calculated to account for the curvature of the facepieces. 

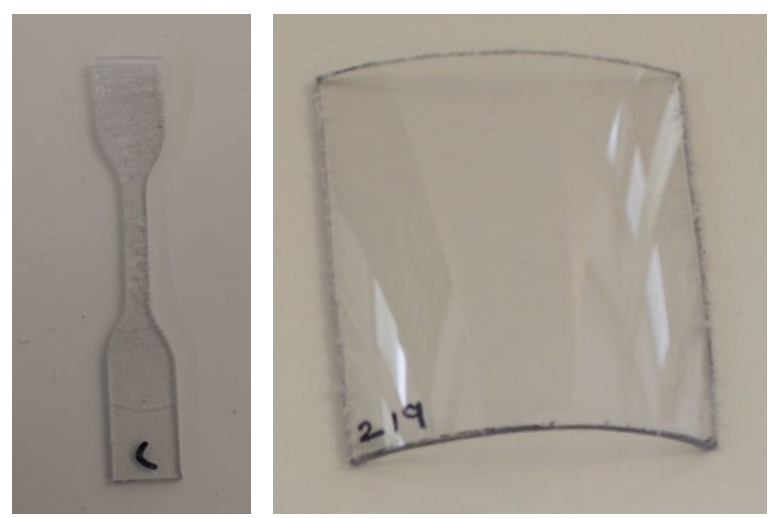

Figure 4. Prepared test samples

\section{Quasistatic Tension Testing}

Constant-displacement tension tests were performed on the dogbone samples taken from the facepieces in accordance with ASTM D638-10 [33] using an MTS Systems Corporation Model 880 servo-hydraulic load frame coupled with an Instron 8500 Plus digital controller, a National Instruments LabVIEW custom data collection program, and an Eaton Corporation Lebow 3173$5002.2 \mathrm{kN}$ load cell (Figure 5). Strain data were collected from select samples using MTS Systems Corporation Model 380041-01 extensometer with a $25.4 \mathrm{~mm}$ gage length and 10\% maximum range. Data collected during tension testing was utilized to determine tensile strength, the modulus of elasticity, and an estimation of strain to failure for the test specimens.
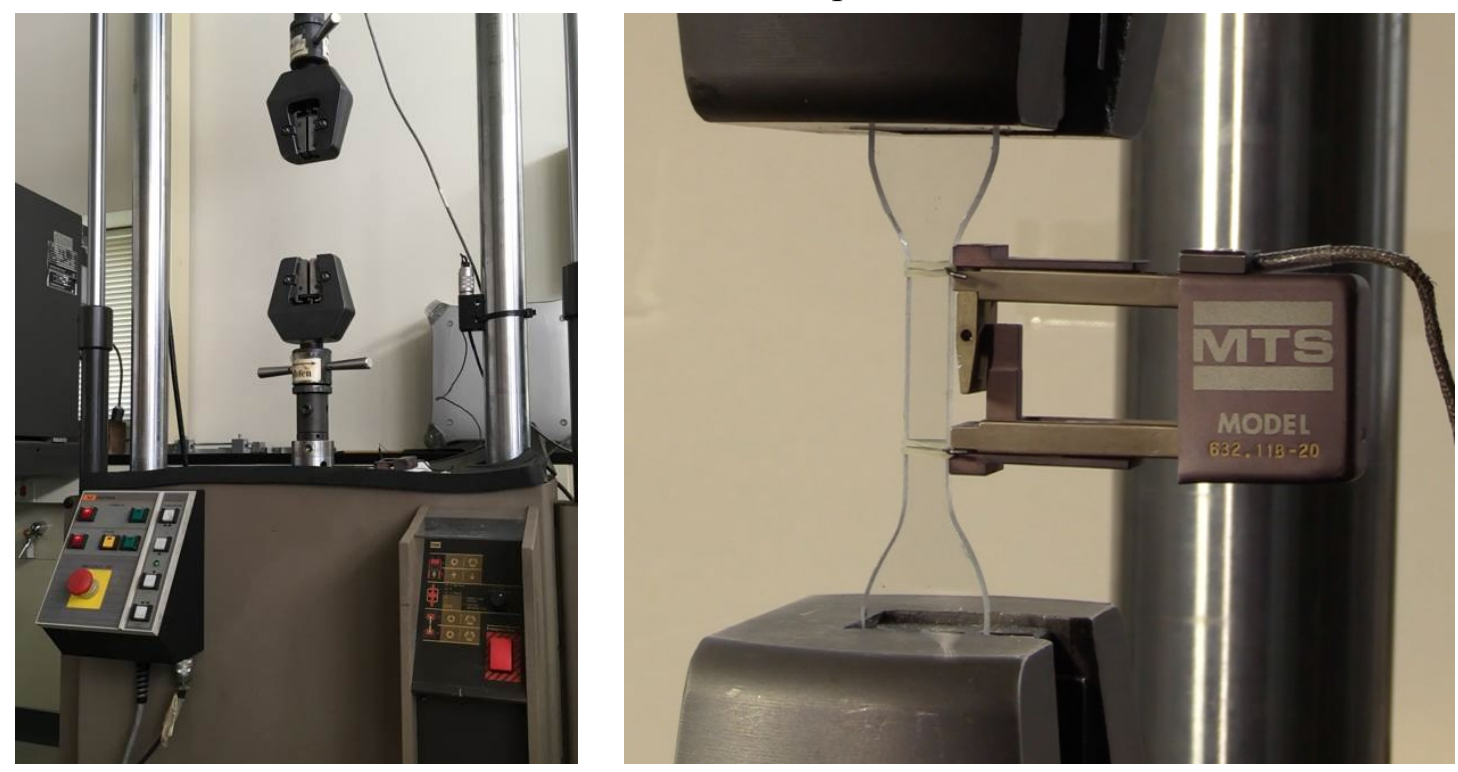

Figure 5: Servo-hydraulic quasistatic tensile test apparatus

Engineering stress and strain values are calculated for each specimen using the crosssectional area calculated from digital caliper measurements, load cell measurements and the change in extensometer gage length. Tensile strength is the maximum stress that was experienced by the specimen during loading. Strain values were recorded along with engineering stress for 
various test specimens in our experiments to calculate the modulus of elasticity using slope of the elastic portion of the stress versus strain curve.

Large deformation of some samples prior to ultimate failure made the use of electromechanical extensometry devices impractical throughout the entire test. Instead, estimated ductility values were determined from the displacement of the hydraulic actuator normalized to the $25.4 \mathrm{~mm}$ gage length. This method introduces potential for error due to slippage in the grips, deformation in areas outside of the $25.4 \mathrm{~mm}$ gage length and the effect of load frame compliance on measured deformation, however it does provide a useful approximation to the ductility of the samples and allow comparison between exposures in a consistent manner.

\section{Dynamic Impact Testing}

An Instron Corporation Dynatup Model 8210 drop tower with a $15.9 \mathrm{~mm}$ instrumented tup was used to conduct dynamic mechanical testing on the facepiece lens samples. Samples were held with a $76 \mathrm{~mm}$ diameter pneumatic clamp, centered around the instrumented tup. The total fracture energy of the lens samples is calculated by integrating the force recorded by the load cell with respect to displacement of the tup. Since the lens specimens are not instrumented to record the deflection of the material during impact, the displacement is computed mathematically by evaluating the motion of the tup as described in NIST GCR 17-014 [30].

Large fracture energies and large post-impact deformation are indicative of ductile mechanical behavior, whereas lower fracture energies and sample failure with multiple pieces or with sharp fracture patterns indicate brittle response.
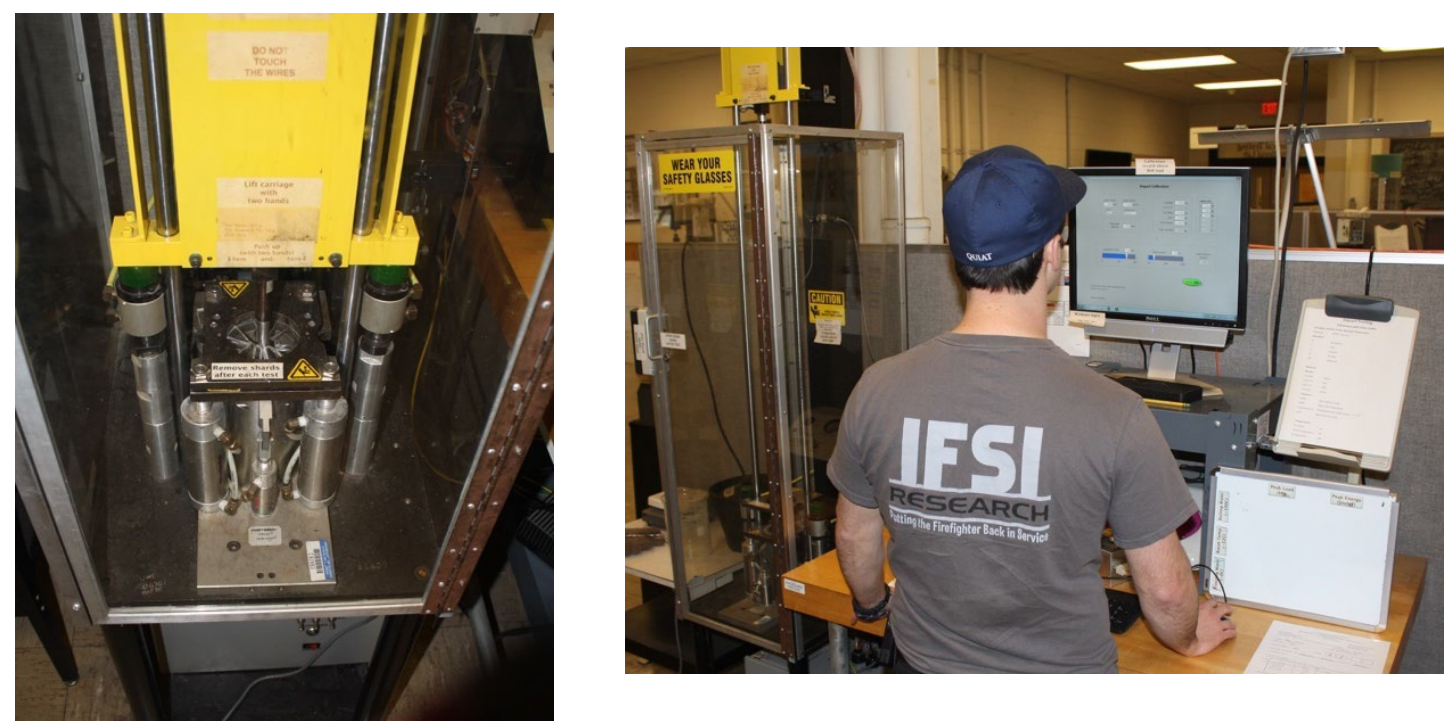

Figure 6: Dynamic mechanical testing apparatus 


\section{$\underline{\text { Statistics }}$}

An ANOVA framework was utilized to determine statistically significant differences in facepiece properties in quasistatic tension tests. Two facepiece models (1-07B vs. 1-13) and three exposure levels (0-0-0 vs $5-5-100$ vs $10-1.5-10)$ were used in a $2 \times 3$ framework to generate comparisons between mechanical properties of the unexposed samples of a specific facepiece and the various exposed samples, while also allowing for comparison between the facepiece models. Post-hoc testing was performed using the Tukey Honestly Significant Difference test to determine significance of interactions between facepiece model and exposure level. Statistical significance was set at $p<0.05$. Impact testing was conducted on single samples, so no statistical analysis was conducted.

\section{Thermal Testing - NFPA 1981 Lens Radiant Heat Testing}

For the Lens Radiant Heat Test, SCBA facepieces were mounted on a breathing headform and exposed to a constant heat flux of $15 \mathrm{~kW} / \mathrm{m}^{2}$ for 5 minutes. After 5 minutes of exposure, the radiant source was removed. Typically, the headform is dropped $150 \mathrm{~mm}$, but this portion of the test was not completed in this study. The facepiece is required to maintain a positive pressure air supply for a total of 24 minutes while breathing at $40 \mathrm{~L} / \mathrm{min}$; any loss of positive pressure during the test results in a failure. The air supply was provided by a cascade air source, so an unlimited supply was available in each test. Additionally, qualitative changes in lens damage were recorded (time to formation of microbubbles, microcracking and hole). This testing was conducted on 1-07B and 1-13 samples in each of the conditions listed in Table 4.

\section{Off-gas Testing}

To quantify the chemicals that may be present within the SCBA facepiece breathing space under elevated thermal conditions (and thus available for the firefighter to inhale), an Agilent 6980N Gas Chromatograph (GC) and 5973N Mass Spectrometer (MS) were employed. Two series of tests were conducted with the GC-MS apparatus:

(1) Sampling while the facepiece lens is exposed to the radiant panel apparatus.

a. Ordinary Fireground Exposure: SCBA facepiece is secured to the headform, which is breathing supplied air from compressed air cylinder at a standard rate of $40 \mathrm{~L} / \mathrm{min}$ under Thermal Class III and IV conditions (high end of Utech's 'Ordinary' [24] category)

b. Emergency Situation: SCBA facepiece material is exposed to Thermal Class IV conditions without airflow. These test were conducted using sections of SCBA material to avoid damage to (and potential off-gassing from) the breathing headform. 
(2) Sampling of liquid injections of SCBA facepieces dissolved in chloroform to identify potential chemicals available to off-gas from the facepieces.

\section{Gas Chromatograph with Mass Spectrometer apparatus}

The GC-MS apparatus consists of four major components (Figure 7). The vacuum pump eliminates contaminants from the sampling train, and maintains a pressure of less than $10^{-6}$ Torr in the system. The gas chromatograph, separates the gas mixture into its components, before it enters the mass spectrometer through the use of a column. The column contains a stationary phase, which is a microscopic layer of liquid or polymer, on an inert solid support, inside a piece of glass. The gaseous compounds being analyzed are transported through the column by the mobile phase which is normally a carrier gas (in this case Helium). As the compounds move through the column, they interact with the walls of the column which is coated with the stationary phase, causing them to elute at different times. The elution time of each compound is called the retention time, and it remains constant if the same test procedure is used. The last part is the mass spectrometer, which is used to identify the various compounds within the injected substance. This is done by ionizing chemical species and sorting them by their mass to charge ratio $(\mathrm{m} / \mathrm{z})$.

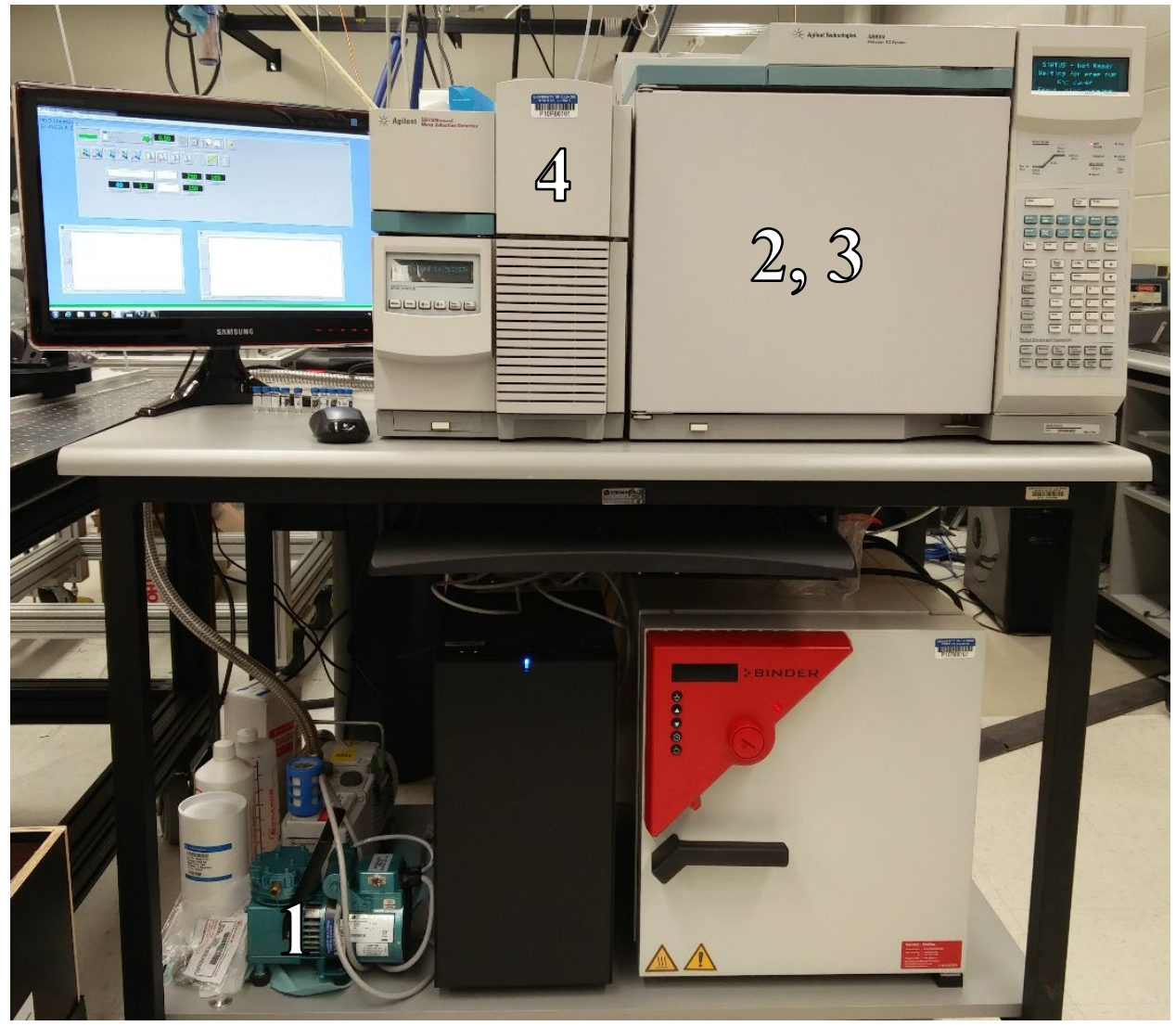

Figure 7. Gas Chromatograph-Mass Spectrometer (GC-MS) system employed in SCBA facepiece testing including vacuum pump (1), GC and column (2,3) and MS (4). 
An Agilent DB-5 Ultra Inert column was employed with a $25 \mu \mathrm{m}$ thick DB-5ms, (5\%-Phenyl)methylpolysiloxane stationary phase applied on the $320 \mu \mathrm{m}$ diameter glass column with total length of $30 \mathrm{~m}$. This column is a non-polar low bleed column and has a high temperature limit. The flow rate of the Helium mobile phase was a constant $1.2 \mathrm{ml} / \mathrm{hr}$. The GC also contains an oven which allows for an additional degree of freedom in experimental design. Increasing the temperature of the column can reduce the elution time of compounds, reducing total test time. The oven temperature ramp used throughout all the experiments is shown in Figure 8. The oven is initially held at $40{ }^{\circ} \mathrm{C}$ for 2 minutes, before ramping to $260^{\circ} \mathrm{C}$ at a rate of $5{ }^{\circ} \mathrm{C} / \mathrm{min}$, followed by a hold for 3 minutes. A slow temperature ramp allows for better separation of the compounds by increasing the retention time between them. Finally, the oven temperature ramps up to $300{ }^{\circ} \mathrm{C}$ at $30{ }^{\circ} \mathrm{C} / \mathrm{min}$, and is held for 10 minutes in order to clear the column of any remaining compounds and prepare it for the next test.

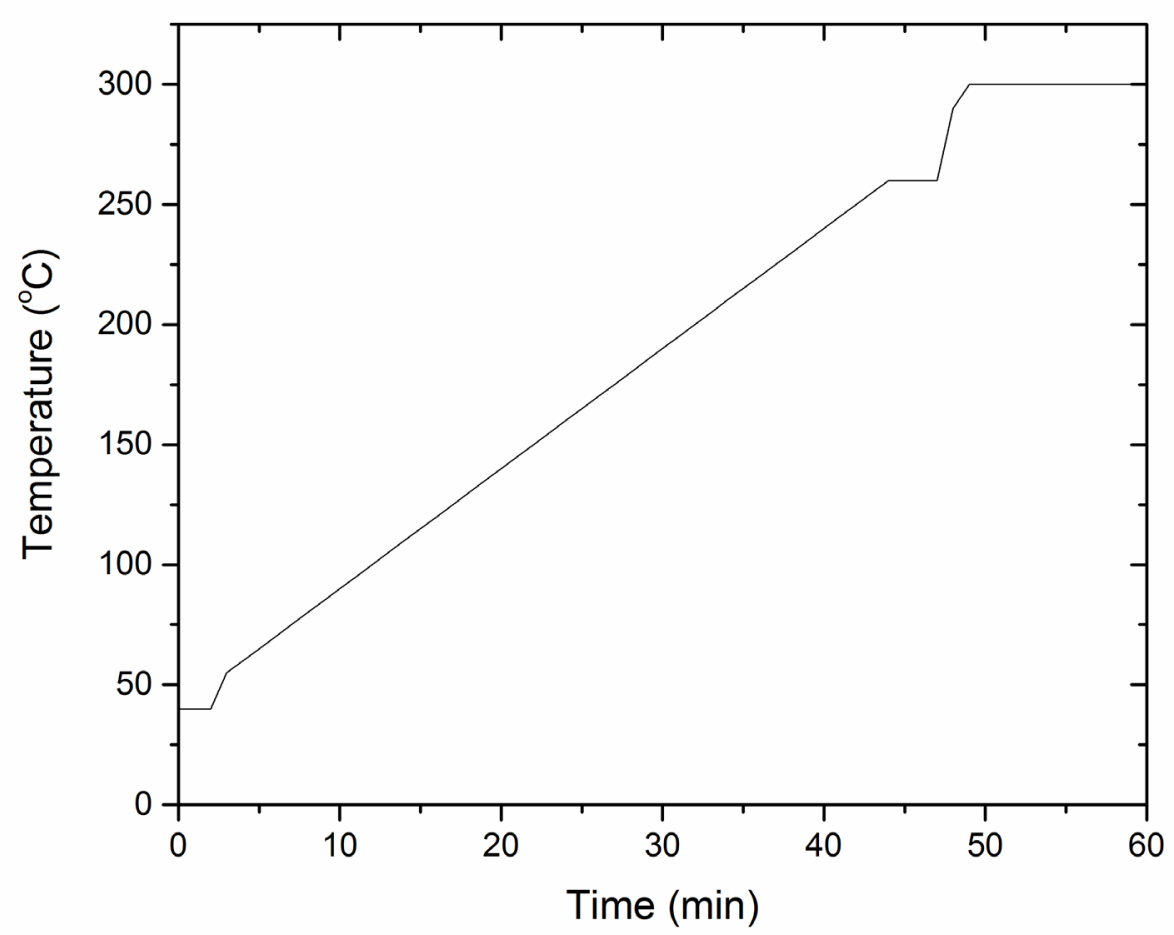

Figure 8. Temperature Ramp utilized for GC Oven

\section{Ordinary Fireground Exposure}

Three regions of interest were identified in the SCBA testing apparatus: 1) In the airway between the headform and bellows as a surrogate for the firefighter's lungs, 2) between the SCBA lens and nose-cone where the highest concentrations of off-gassing might be expected (prior to mixing with incoming SCBA air during a breath) and 3) at the mouth where breathing air would enter the firefighter's body (Figure 9). Gas was sampled from these three locations and injected into the 
GC-MS through the use of the air pump at $138 \mathrm{kPa}(20 \mathrm{psi})$. SCBA facepieces were tested under a wide variety of heat flux conditions, with injection occurring when the inside surface of the lens reached the target temperatures shown in Table 5. In some cases, the SCBA facepieces were exposed through their glass transition temperatures, started to craze, and began to form a hole.
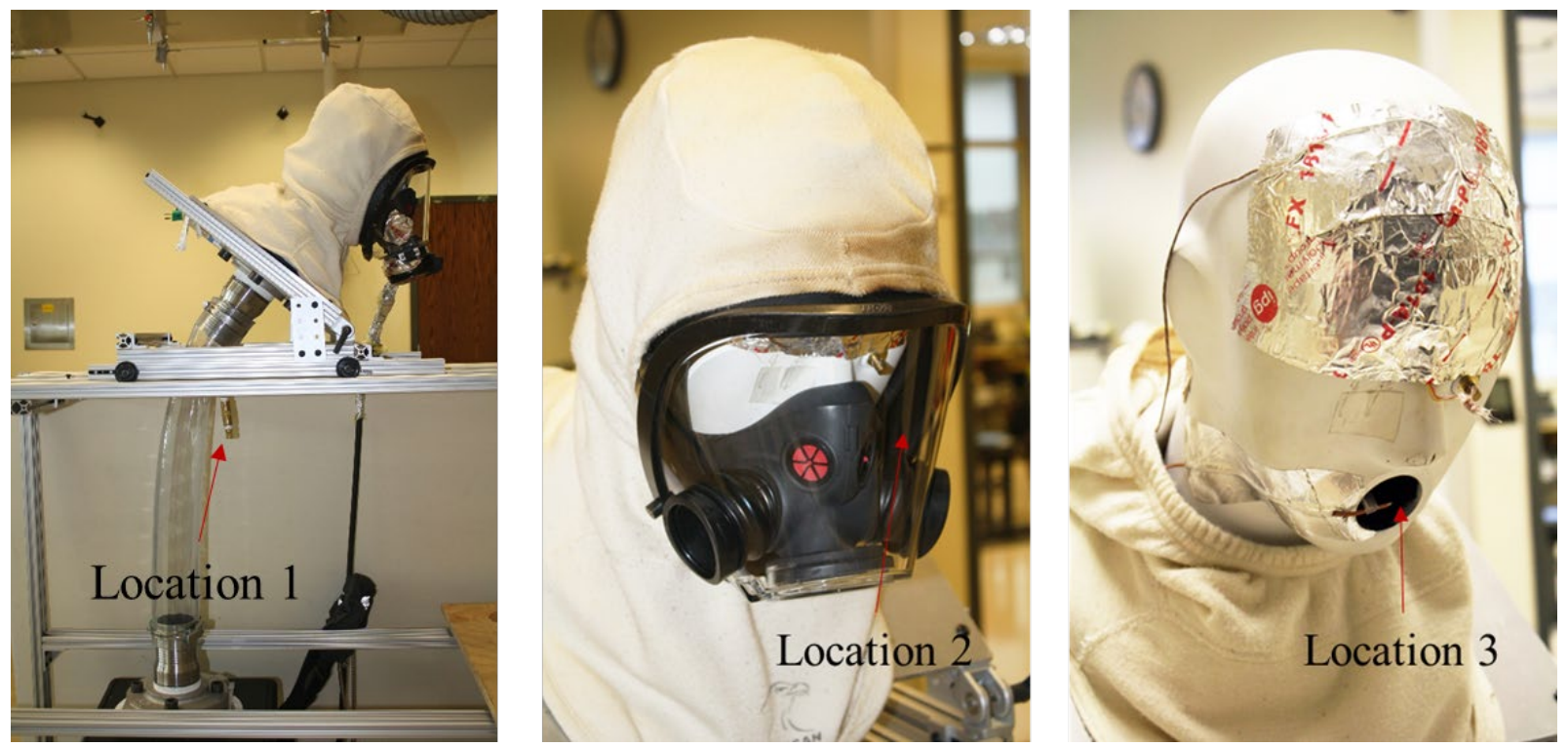

Figure 9. Sampling locations for gaseous injection in the GC-MS. Sampling in the airway (Location 1), between the SCBA lens and nose-cone (Location 2), and at the mouth (Location 3).

Table 5. Test conditions for SCBA facepieces. Gas samples were taken at the target temperature under the various heat fluxes.

\begin{tabular}{|c|c|c|c|}
\hline $\begin{array}{c}\text { Target temperature of inside lens } \\
\text { surface at the gas sampling time }\left({ }^{\circ} \mathrm{C}\right)\end{array}$ & \multicolumn{3}{c|}{$\begin{array}{c}\text { Heat Flux } \\
\left(\mathrm{kW} / \mathrm{m}^{2}\right)\end{array}$} \\
\hline $\mathbf{5 0}$ & 5 & 10 & -- \\
\hline $\mathbf{7 0}$ & 5 & 10 & 12 \\
\hline $\mathbf{1 0 0}$ & -- & 10 & 12 \\
\hline Hole Formation & -- & -- & 12 \\
\hline
\end{tabular}

Emergency Situation

In addition to these tests with the breathing mannequin, sectioned samples of the SCBA facepieces were mounted directly in front of the radiant heat panel, without the headform and the breathing apparatus (Figure 10). Gas samples were collected both behind the facepiece (firefighter side) as well as in front of the facepieces (radiant panel side) where off-gassing was visible. Gas samples were collected prior to craze formation, during crazing, and during bubble formation (Figure 11). This test illustrated a scenario where the SCBA facepiece has no cooling from incoming breathing air while being exposed to a high heat flux. 


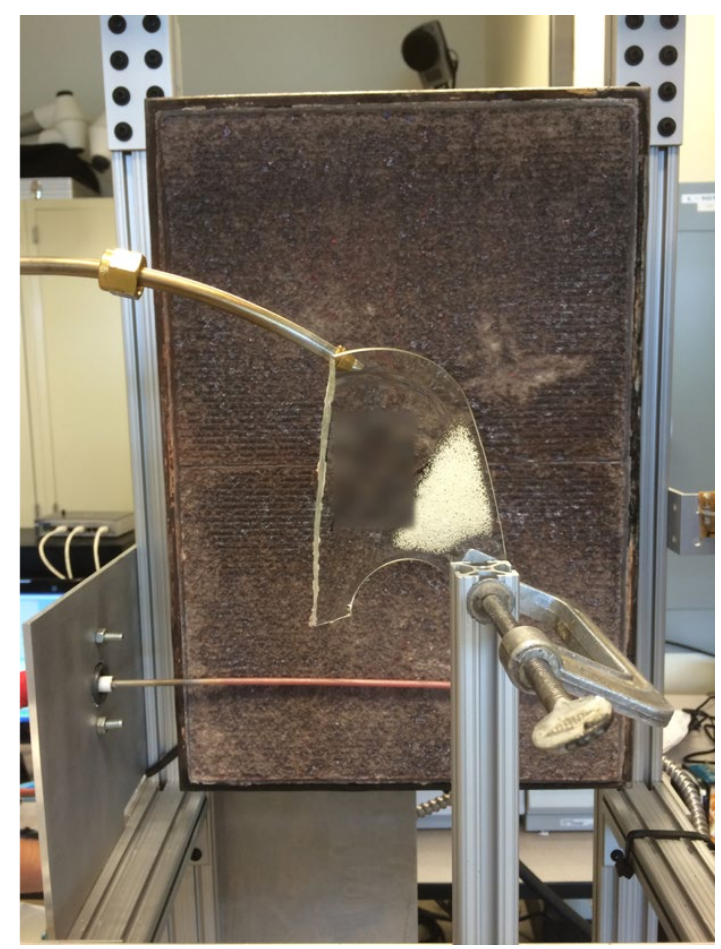

Figure 10. Experimental setup for GC-MS off-gas testing under extreme condition.
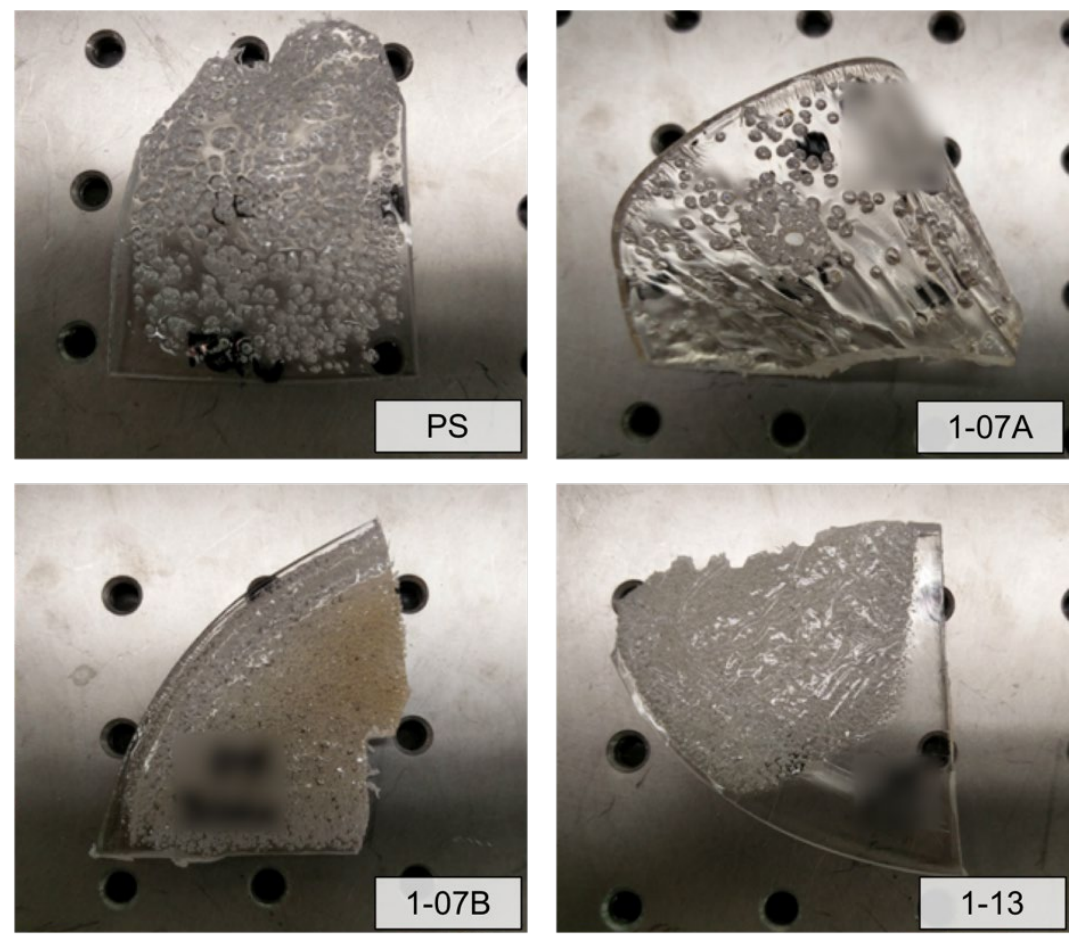

Figure 11. SCBA facepiece sections subjected to high heat flux until bubble occurrence. 


\section{Liquid Injections}

To determine the chemical compounds utilized in the SCBA facepiece materials (that might potentially be available for off-gassing at elevated temperatures), samples harvested from the SCBA facepieces were injected in a liquid form into the GC-MS. Two sets of samples were used, 1) new samples with no previous thermal exposure (unexposed), and 2) those from the 'Emergency Situation' (exposed) shown in Figure 11. Both sets of samples were dissolved in chloroform and injected in the GC-MS. This approach allows the direct comparison of the exposed samples to their unexposed counterparts, as well as a direct comparison between the SCBA facepieces themselves. Samples were prepared by cutting a small piece of the SCBA facepiece weighing in the range of $\sim 30-60 \mathrm{mg}$, which was then dissolved with $\sim 1.4-1.5 \mathrm{ml}$ of chloroform for 6 days at $23^{\circ} \mathrm{C}$ (Figure 12). Table 6 summarizes their individual weights for each sample, as well as their concentrations within the solvent solution. The samples were measured using a high-fidelity laboratory scale with accuracy to within $1 \mathrm{mg}$. The uncertainty on the mass measurements was calculated to be less than $0.1 \%$.

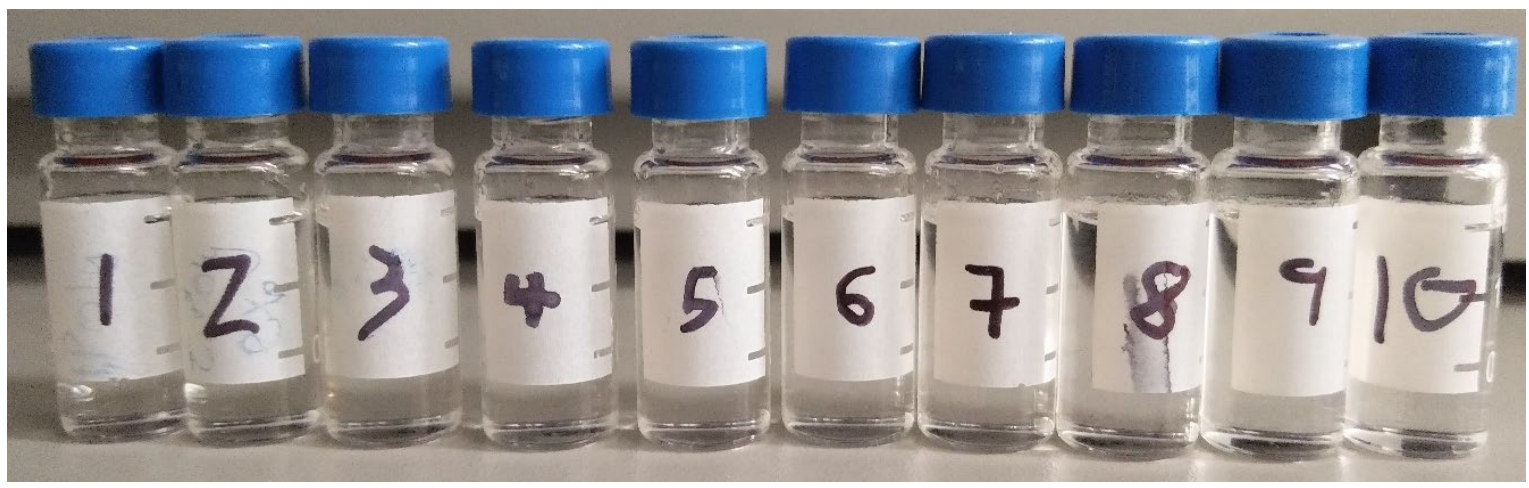

Figure 12. Prepared liquid samples in glass containers.

Table 6. SCBA facepiece sample weights and solvent concentrations.

\begin{tabular}{|c|c|c|c|c|}
\hline \multirow{2}{*}{ SCBA Facepiece } & Conditions & $\begin{array}{c}\text { Sample } \\
\text { Mass } \\
(\mathrm{mg})\end{array}$ & $\begin{array}{c}\text { Chloroform } \\
\text { Solvent }(\mathrm{ml})\end{array}$ & $\begin{array}{c}\text { Solute } \\
\text { Concentration } \\
(\mathrm{g} / \mathrm{ml})\end{array}$ \\
\hline \multirow{3}{*}{ 1-07A } & Unexposed & 52 & 1.52 & 34.3 \\
\cline { 2 - 5 } & Exposed & 58 & 1.42 & 40.7 \\
\hline \multirow{2}{*}{$1-07 B$} & Unexposed & 58 & 1.46 & 39.7 \\
\cline { 2 - 5 } & Exposed & 61 & 1.52 & 40.2 \\
\hline \multirow{2}{*}{$1-13$} & Unexposed & 44 & 1.51 & 29.1 \\
\cline { 2 - 5 } & Exposed & 51 & 1.47 & 34.7 \\
\hline \multirow{2}{*}{ PS } & Unexposed & 31 & 1.53 & 20.3 \\
\cline { 2 - 5 } & Exposed & 41 & 1.45 & 28.2 \\
\hline
\end{tabular}




\section{Results}

\section{Mechanical Testing}

Quasistatic Tension Testing

Representative quasistatic load-displacement curves for the two facepiece models and three thermal conditions are shown in Figure 13. Facepiece models are differentiated by line patterns (Solid 1-07B; Dashed 1-13), while the thermal exposures can be identified by line colors (Blue, 00-0; Green, 5-5-100; Red, 10-1.5-10) to allow comparison. Table 7 indicates the number of samples reported in each test condition, while Table 8 shows a summary of the quasistatic tensile test results from these samples. With the 2x3 ANOVA framework, it is possible to compare main effects of facepiece model and exposure type.

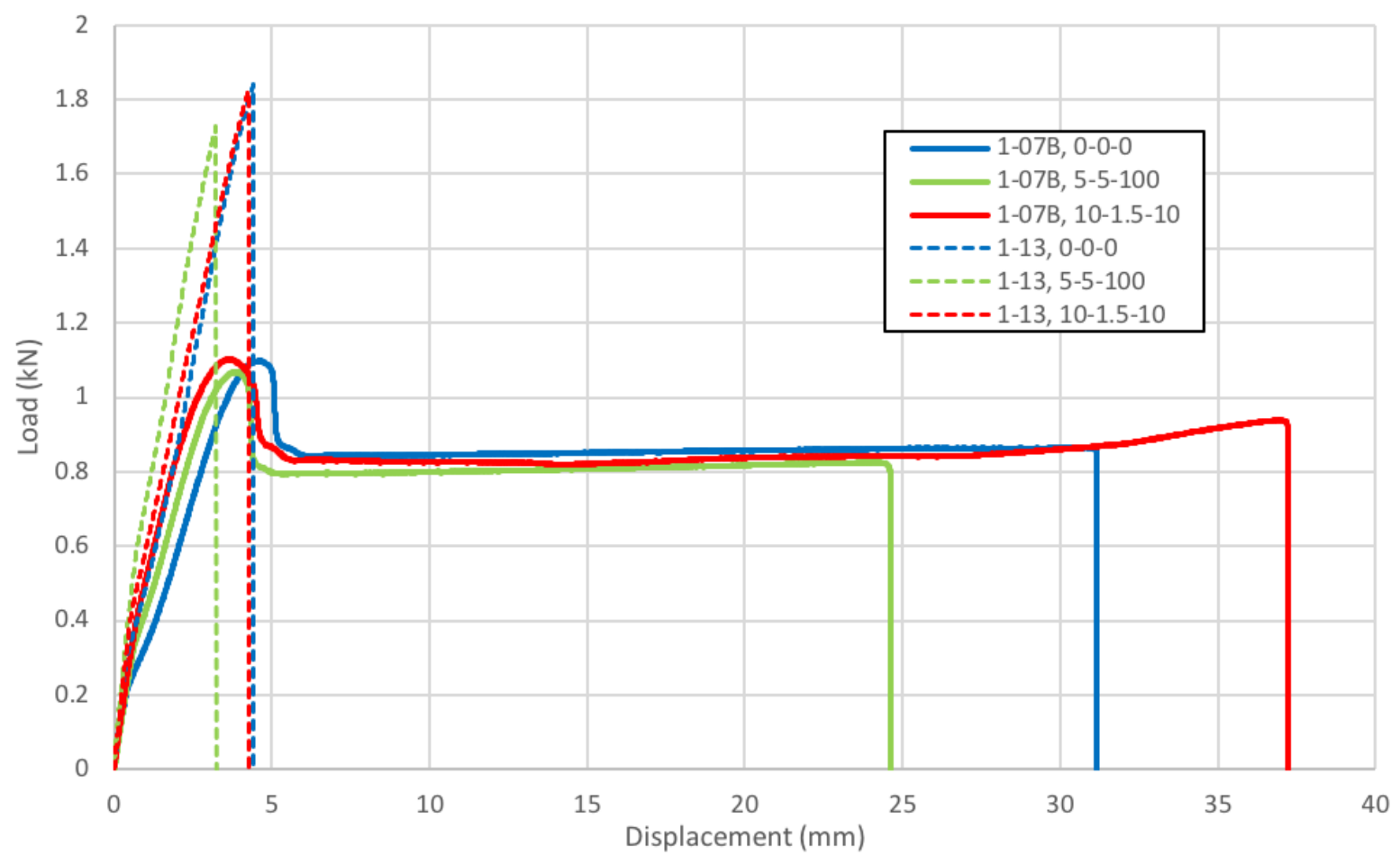

Figure 13. Quasistatic load-displacement plots for representative samples from each facepiece and exposure condition. 
Table 7. Number of samples utilized in quasistatic tests.

\begin{tabular}{|c|c|c|c|c|}
\cline { 3 - 5 } \multicolumn{2}{c|}{} & \multicolumn{3}{c|}{ Number of Samples (n) } \\
\hline \multirow{2}{*}{$\begin{array}{c}\text { Sample Exposure } \\
\text { (kW-minutes-cycles) }\end{array}$} & $\begin{array}{c}\text { Facepiece } \\
\text { Type }\end{array}$ & $\begin{array}{c}\text { Tensile } \\
\text { Strength }\end{array}$ & $\begin{array}{c}\text { Elastic } \\
\text { Modulus }\end{array}$ & $\begin{array}{c}\text { Strain to } \\
\text { Failure }\end{array}$ \\
\hline \multirow{2}{*}{$\begin{array}{c}\text { (Unexposed) } \\
\text { 1-07A* }\end{array}$} & 13 & 13 & 13 \\
\cline { 2 - 5 } & $1-07 \mathrm{~B}$ & 10 & 5 & 10 \\
\cline { 2 - 5 } & $1-13$ & 10 & 4 & 10 \\
\hline \multirow{3}{*}{$5-5-100$} & $1-07 \mathrm{~A}^{*}$ & 15 & 15 & 15 \\
\cline { 2 - 5 } & $1-07 \mathrm{~B}$ & 10 & 5 & 5 \\
\cline { 2 - 5 } & $1-13$ & 10 & 4 & 6 \\
\hline \multirow{2}{*}{$10-1.5-10$} & $1-07 \mathrm{~B}$ & 15 & 8 & 7 \\
\cline { 2 - 5 } & $1-13$ & 10 & 7 & 5 \\
\hline
\end{tabular}

* From NIST GCR 17-014 [30]

Table 8. Summary of quasistatic tensile test results from each facepiece at both exposure conditions compared to baseline unexposed samples.

\begin{tabular}{|c|c|c|c|c|}
\hline $\begin{array}{c}\text { Sample Exposure } \\
\text { (kW-minutes-cycles) }\end{array}$ & $\begin{array}{l}\text { Facepiece } \\
\text { Type }\end{array}$ & $\begin{array}{c}\text { Tensile } \\
\text { Strength }^{\dagger \ddagger} \\
(\mathrm{MPa})\end{array}$ & $\begin{array}{c}\text { Elastic } \\
\text { Modulus }^{+} \\
(\mathrm{GPa})\end{array}$ & $\begin{array}{l}\text { Strain to Failure }{ }^{\dagger \ddagger} \\
\qquad(\mathrm{mm} / \mathrm{mm})\end{array}$ \\
\hline \multirow{3}{*}{$\begin{array}{c}\text { 0-0-0 } \\
\text { (Unexposed) }\end{array}$} & 1-07A* & $65.8 \pm 1.9$ & $2.21 \pm 0.12$ & $1.37 \pm 0.15$ \\
\hline & 1-07B & $66.4 \pm 1.0$ & $2.27 \pm 0.09$ & $1.17 \pm 0.27$ \\
\hline & $1-13$ & $74.1 \pm 2.0$ & $2.54 \pm 0.27$ & $0.17 \pm 0.02$ \\
\hline \multirow{3}{*}{$5-5-100$} & $1-07 A^{*}$ & $70.5 \pm 3.2$ & $2.19 \pm 0.15$ & $0.77 \pm 0.44$ \\
\hline & $1-07 B$ & $68.3 \pm 1.6$ & $2.30 \pm 0.08$ & $0.76 \pm 0.27$ \\
\hline & $1-13$ & $67.2 \pm 2.6$ & $2.29 \pm 0.07$ & $0.13 \pm 0.01$ \\
\hline \multirow{2}{*}{$10-1.5-10$} & 1-07B & $65.2 \pm 3.1$ & $2.18 \pm 0.17$ & $1.28 \pm 0.22$ \\
\hline & $1-13$ & $72.5 \pm 3.6$ & $2.34 \pm 0.10$ & $0.14 \pm 0.02$ \\
\hline
\end{tabular}

* From Table 5 of NIST GCR 17-014[30] for reference

†Facepiece main effect. Significant difference between facepiece models (1-07B vs. 1-13, $p<0.05)$.

¥ Exposure main effect. Significant difference between exposures (Unexposed vs. 5-5-100 vs. 10$1.5-10, p<0.05)$

Bold indicates statistically significant difference compared to the unexposed sample of the same facepiece type $(p<0.05)$. 
Statistically significant differences were found between facepiece models for all three quasistatic tensile properties. Tensile strength, elastic modulus, and strain to failure were significantly different between facepieces ( $p<0.001, p=0.011, p<0.001$; respectively). 1-13 facepieces had higher tensile strength and elastic modulus, but lower strain to failure. The 1-13 material can carry a much higher load prior to failure, but fails in a more brittle manner (limited ductility or 'stretch' prior to failure) than the 1-07B material. During tension testing both the 107A and 1-07B facepieces displayed highly ductile behavior prior to failure - greater than $100 \%$ strain at failure for the unexposed samples while the 1-13 facepiece displayed brittle behavior with minimal necking and less than $20 \%$ strain to failure (Figure 14). Data from the 1-07A facepieces from NIST GCR 17-014 [30] are provided for comparison.

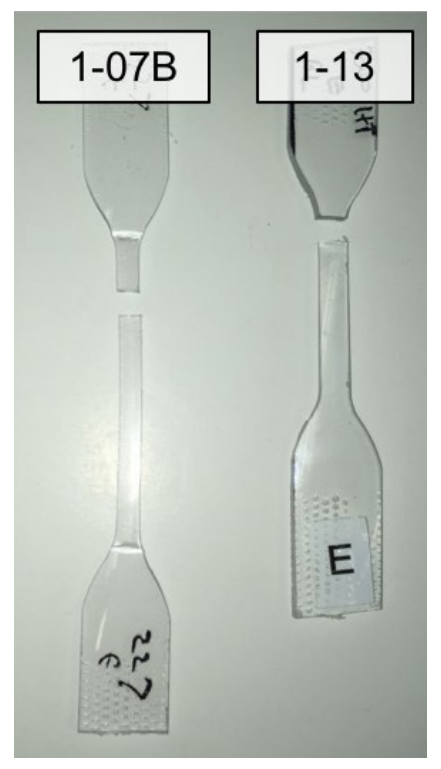

Figure 14. Representative samples of elongation following quasistatic tensile testing of unexposed facepiece sections.

Statistically significant differences due to thermal exposure prior to mechanical testing are highlighted in bold on Table 8 . Both tensile strength and strain to failure were significantly affected by exposure ( $p=0.011, p=0.002$; respectively). Post-hoc analysis revealed that the 10-1.5-10 condition did not result in a statistically significantly impact on strength compared to unexposed facepieces, but the 5-5-100 condition resulted in statistically significant differences in tensile strength for both facepiece models ( $p<0.001$ for both). 1-07B facepieces showed a slight increase (1.9 MPa or $\sim 3 \%$ ) in tensile strength, while 1-13 showed a significant decrease of about $7 \mathrm{MPa}$ $(\sim 9 \%)$. Samples from both the 1-07A [30] and 1-07B reached a higher tensile strength after exposure to the $5 \mathrm{~kW} / \mathrm{m}^{2}$ test when compared to their respective unexposed samples. This increase in strength came at a tradeoff with loss in ductility $(p=0.002)$. After the 5-5-100 test, ductility of the 1-07B samples was on average $0.41 \mathrm{~mm} / \mathrm{mm}(35 \%)$ lower than the $0-0-0$ samples and failure 
occurred at a similar strain as the 1-07A samples after exposure to 5-5-100 conditions (0.76 vs 0.77). Strain to failure for the 1-13 samples after the 5-5-100 exposure was also slightly reduced, but the change was statistically not signifcant. Again, the 10-1.5-10 condition had no statistically sigificant impact on strain to failure of either facepiece material.

A possible explanation for change in properties observed in the pre-2013 edition facepices is that as the materials of the facepiece were heated and cooled repeatedly while under positive pressure, they may have undergone a form of heat treatment and potentially molecular reorientation that caused the facepiece to become stronger and more brittle. Further investigation into the properites of the facepieces and effects of such heat treatment would need to be conducted to obtain a better understanding of why this occurred. By contrast, the 1-13 facepiece with the same exposure resulted in only slight reductions in both strength (statistically significant) and ductility (not significant). The 1-13 facepiece material was thicker and more stiff than the samples from the 1-07A and 1-07B models $(3.8 \mathrm{~mm}$ vs $2.6 \mathrm{~mm}$ and $2.0 \mathrm{~mm})$, which may have reduced the impact of this cyclic loading effect. It is important to note that while statistically significant changes in strength are noted here, these materials remain quite strong when tested at room temperature.

The 1-07B and 1-13 facepieces exposed to the 10-1.5-10 condition resulted in minimal changes in mechanical properties when compared to the unexposed samples. In fact, for the both facepiece models, there were no significant differences between the unexposed facepieces and those exposed to the 10-1.5-10 condition. After exposure to the 10-1.5-10 condition, the 1-07B facepieces had noticable microcracking (Figure 15) which was not present after the 5-5-100 condition. Interestingly, these visible indiations of damage did not translate to changes in quasistatic mechanical properties, while significant degradations in ductility were noted after 5-5100 despite no visible thermal damage.
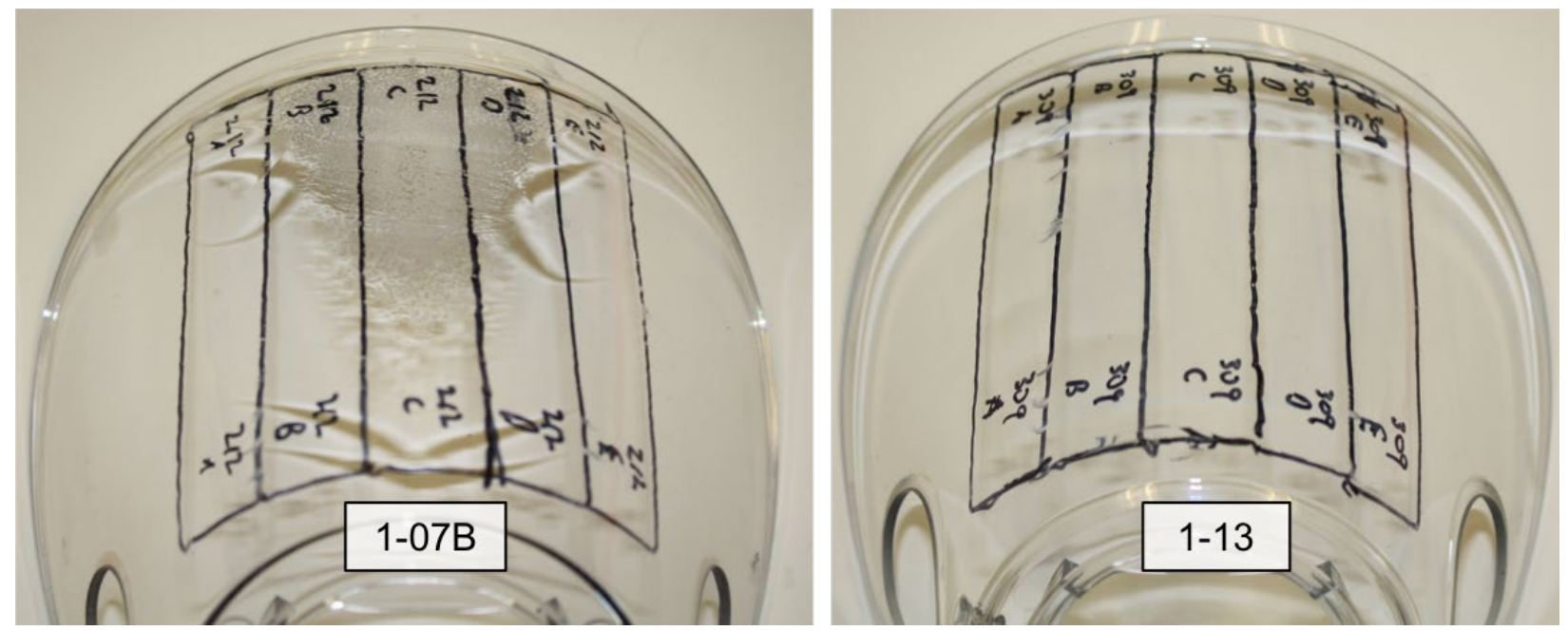

Figure 15. 1-07B and 1-13 facepiece showing damage from thermal exposure (10-1.5-10) prior to sample harvesting. 


\section{Dynamic Impact Testing}

Representative dynamic load-time plots from each of the facepiece samples and exposure conditions can be found in Figure 16 with results summarized in Table 9. While the sample size did not allow statistical analysis, a few interesting observations can be made. The 1-13 facepiece samples reached the highest load before failure for each of the three facepiece exposure conditions. However, energy absportion prior to failure was not as consistent; while the unexposed 1-13 sample absorbed more energy than the unexposed 1-07B sample, energy absorption was similar after the 5-5-100 condition, and after then 10-1.5-10 condition, the 1-13 sample absorbed less energy than the 1-07B sample. The 5-5-100 exposure resulted in relatively small changes in dynamic mechanical properties when compared to their unexposed samples. In contrast, after exposure to the 10-1.5-10 condition both facepiece samples failed at a notably lower maximum load and lower energy absorption relative to the unexposed condition. It should be noted, while these thermal exposures resulted in measureable change in dynamic mechancial properties, these exposed samples failed at higher loads and absorbed more energy than the unexposed 1-07A samples tested in NIST GCR 17-014 [30].

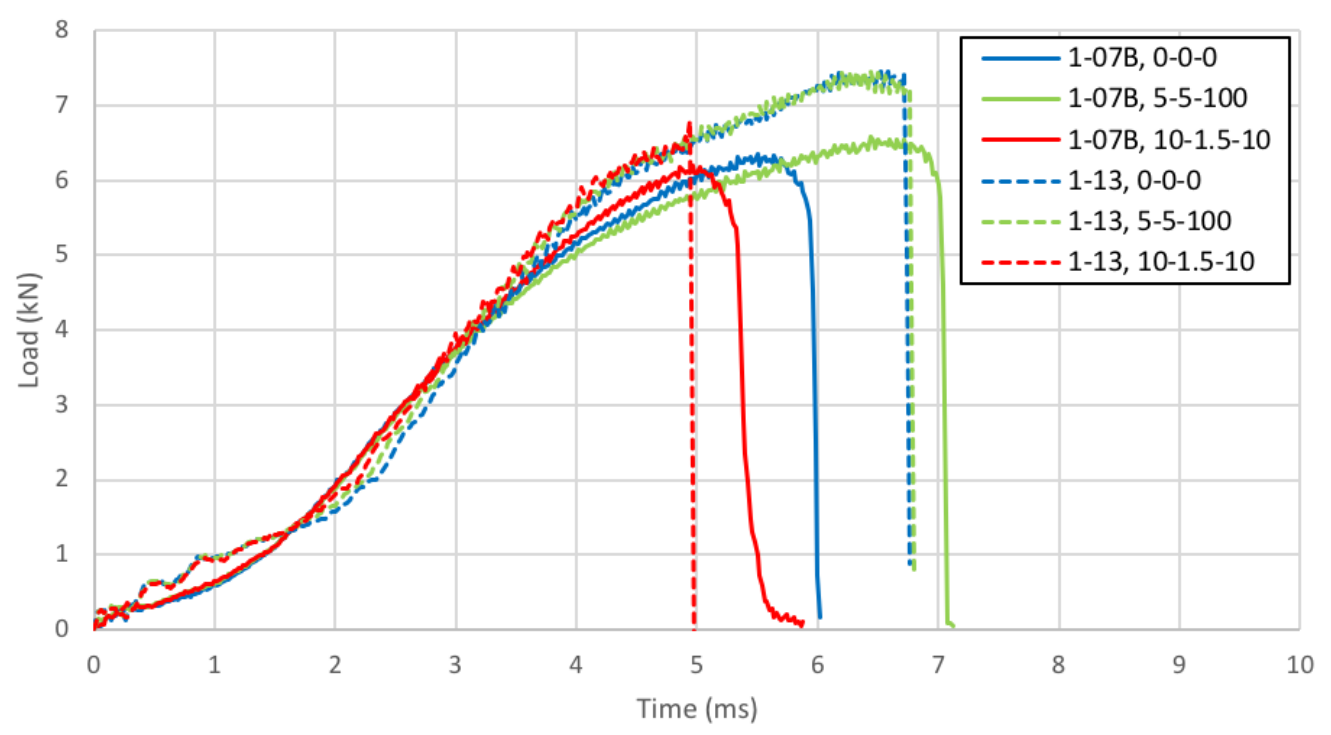

Figure 16: Dynamic load-time plots for impact tested samples from each facepiece and exposure condition. 
Table 9: Summary of impact test results from each facepiece and exposure conditions.

\begin{tabular}{|c|c|c|c|}
\hline $\begin{array}{c}\text { Sample Exposure } \\
\text { (kW-minutes-cycles) }\end{array}$ & $\begin{array}{c}\text { Facepiece } \\
\text { Type }\end{array}$ & Max Load (kN) & Energy absorbed (J) \\
\hline \multirow{2}{*}{$\begin{array}{c}\text { 0-0-0 } \\
\text { (Unexposed) }\end{array}$} & $1-07 A^{*}$ & 4.19 & 42.88 \\
\cline { 2 - 4 } & $1-07 \mathrm{~B}$ & 6.35 & 58.66 \\
\cline { 2 - 4 } & $1-13$ & 7.47 & 65.40 \\
\hline \multirow{2}{*}{$5-5-100$} & $1-07 \mathrm{~B}$ & 6.59 & 65.40 \\
\cline { 2 - 4 } & $1-13$ & 7.45 & 65.70 \\
\hline \multirow{2}{*}{$10-1.5-10$} & $1-07 \mathrm{~B}$ & 6.20 & 53.16 \\
\cline { 2 - 4 } & $1-13$ & 6.80 & 49.12 \\
\hline
\end{tabular}

*Average from Table 6 in NIST GCR 17-014 [30], all other data points are single sample

Even after repeated heat exposures, these materials are very tough, carrying high loads and absorbing significant amounts of energy prior to failure. Facepiece models conforming to the 2013 standard (1-13) achieved the highest load carrying capacity for all three exposure categories. However, the mechanism of failure was quite different between the models (Figure 17). During impact testing the 1-07A and 1-07B samples all experienced extensive deformation in the center of the sample prior to failure and failed with the tup punching through the thickness with the sample remaining intact. In contrast, the 1-13 facepiece shattered into multiple fragments on impact and the center piece of the facepiece only displayed minor deformation at the point of loading. When this material does eventually fail, the pattern is indicative of a brittle failure and the resulting pieces may be sharp and may travel a considerable distance from the point of impact.

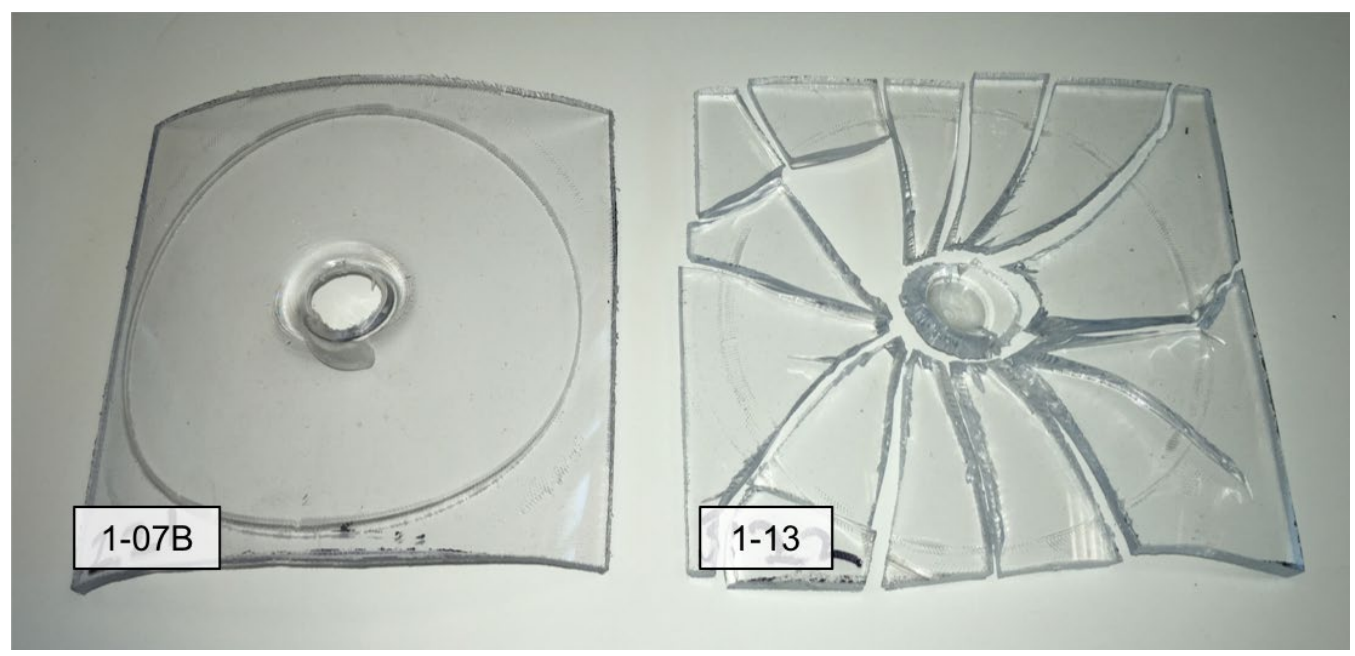

Figure 17. Unexposed facepiece lenses after dynamic impact testing (left to right: 1-07B, 1-13).

In contrast to the quasistatic test results, the higher intensity exposure (10-1.5.10) appears to have an important impact on dynamic properties, particularlly for the more brittle materials used 
in the 1-13 sample. This trend is particularly notable considering the lack of visible indications of thermal damage in the 1-13 mask after this exposure (Figure 17). As shown in Figure 15, this higher intensity exposure resulted in microcracking and bubbling in the 1-07B samples, which may have acted as a dynamic stress concentrator during the high strain rate loading here, but did not result in any changes for the slower tests where there may be more time for molecular reorientation.

\section{NFPA 1981 Lens Radiant Heat Testing}

Facepieces of both models and exposure to all three conditions were subjected to the NFPA 1981 Lens Radiant Heat Test. Throughout the 5 minute, $15 \mathrm{~kW} / \mathrm{m}^{2}$ exposure and 24 minute postexposure test, facepieces were monitored for four visually identifiable changes in the lens material: 1) microcracking (small hairline cracks in the lens which did not appreciably affect visibility through the lens), 2) bubbling (generation of small bubbles which noticably reduced visibility through the lens, 3) pulsation (movement of a the lens in response to pressure changes from the breathing headform), 4) hole formation (creation of an opening between the interior and exterior of the facepiece). The time at which each event occurred (Table 10), graphical representation of time to each event (Figure 18), and visual representation of the progression of facepiece lens damage (Figure 19) are shown below.

All of the tested facepieces, even those that were exposed to the harshest thermal condition (10-1.5-10) prior to the Lens Radiant Heat Tests, maintained positive pressure for the full duration of the test (24 minutes) as indicated in NFPA 1981. However, there were notable differences in the development of damage within each type of facepiece. Regardless of prior thermal exposure, 1-07B samples damage accumulated rapidly, leading to hole formation in approximately 3 minutes or less. On the other hand, the 1-13 lenses never transitioned to hole formation. Further, bubbling typically occurred almost a full minute later in the 1-13 facepiece than in the 1-07B facepiece, which would allow more time before visual acuity is affected.

Damage evolution during the Lens Radiant Heat Tests were minimally impacted following exposure to the 5-5-100 condition in both facepiece samples. It is worth noting that visual pulsation was never identified in the exposed 1-13 sample (even when reviewing video evidence post-hoc). After completion of the 10-1.5-10 exposure, the 1-07B lens had already experienced microcracking. When subsequently exposed to the Lens Radiant Heat Test, the time to bubbling, pulsation and hole formation was reduced compared to the 0-0-0 and 5-5-100 samples, possibly due to this preexisting damage. In contrast, the 10-1.5-10 condition had minimal impact on the 113 sample damage evolution, where bubbling started prior to $2 \frac{1}{2}$ minutes but neither pulsation nor hole formation was noted. 
Table 10. Summary of time to event for NFPA 1981 Lens Radiant Heat Tests.

\begin{tabular}{|c|c|c|c|c|c|}
\hline $\begin{array}{c}\text { Sample } \\
\text { Exposure } \\
\text { (kW-minutes- } \\
\text { cycles) }\end{array}$ & $\begin{array}{c}\text { Facepiece } \\
\text { Type }\end{array}$ & Microcracking & Bubbling & Pulsation & $\begin{array}{c}\text { Hole } \\
\text { Formation }\end{array}$ \\
\hline \multirow{2}{*}{$\begin{array}{c}\text { 0-0-0 } \\
\text { Unexposed }\end{array}$} & 1-07B & $0: 55$ & $1: 17$ & $1: 28$ & $2: 57$ \\
\hline & $1-13$ & $1: 25$ & $2: 15$ & $3: 40$ & -- \\
\hline \multirow{2}{*}{$5-5-100$} & $1-07 B$ & $0: 51$ & $1: 15$ & $1: 45$ & $3: 03$ \\
\hline & $1-13$ & $1: 20$ & $2: 10$ & -- & -- \\
\hline \multirow{2}{*}{$10-1.5-10$} & 1-07B & 0:00 (from exposure) & $0: 59$ & $1: 20$ & $2: 28$ \\
\hline & $1-13$ & $1: 24$ & $2: 24$ & -- & -- \\
\hline
\end{tabular}

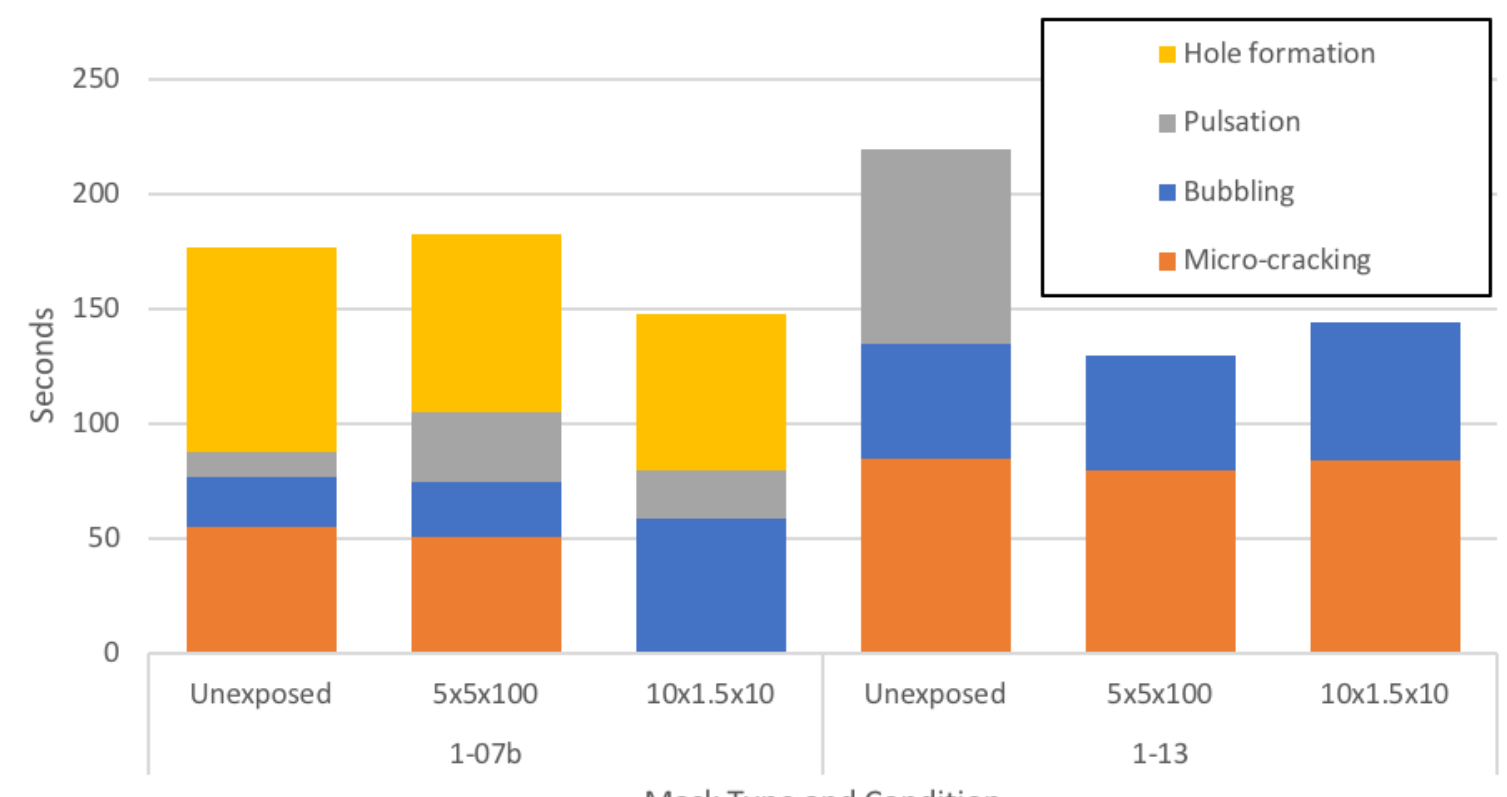

Mask Type and Condition

Figure 18. Time to event for NFPA 1981 Lens Radiant Heat Tests. Note that two of the 1-13 facepieces never accumulated damage beyond bubbling. 


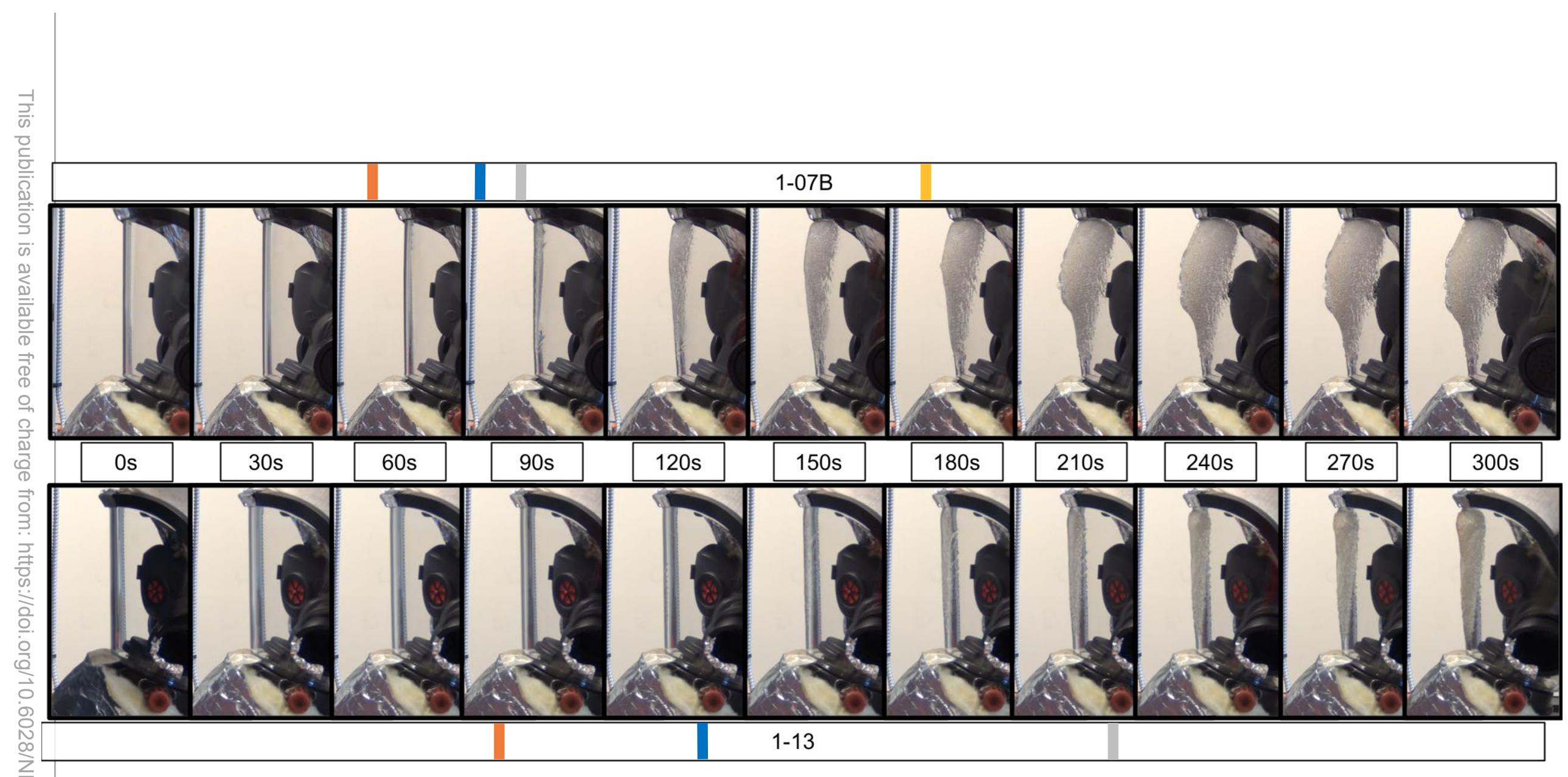

Figure 19. Damage progression on unexposed facepiece lenses during NFPA1981 Lens Radiant Heat Test (1-07B, top; 1-13, bottom). Colored bars indicate time of event. 


\section{Off-gas Testing}

Gaseous Sample Injections

No visible off-gassing from the SCBA facepieces was noted during testing when the facepieces were secured to the breathing headform. In general, air was the only component that was distinguished from the Total Ion Chromatogram (TIC). A representative TIC is shown in Figure 20. The single peak in the TIC was determined to be air, by extracting the respective ions for Nitrogen and Oxygen, $28 \mathrm{~m} / \mathrm{Z}$ and $32 \mathrm{~m} / \mathrm{Z}$ respecitively (where $\mathrm{m} / \mathrm{Z}$ denotes the mass-to-charge ratio), and comparing their mass ratio to that of air (3.29).
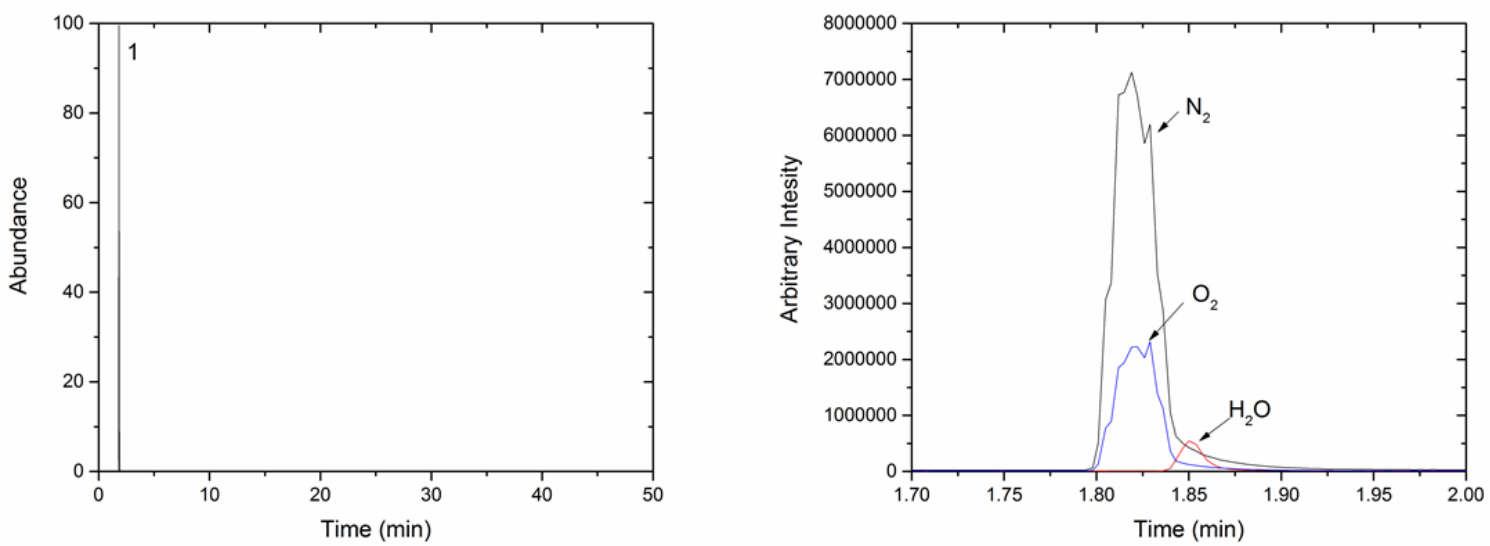

Figure 20. Total Ion Chromatogram from representative sample of gaseous injection of samples collected inside the SCBA facepiece tests (Note peak labelled 1, Left). Extracted Ions for Nitrogen ( $\left.\mathrm{N}_{2}\right)$, Oxygen $\left(\mathrm{O}_{2}\right)$ and Water $\left(\mathrm{H}_{2} \mathrm{O}\right)$ (Right).

This finding is particularly interesting because visible structural damage was observed on the SCBA facepieces in many cases in the form of crazing, bubbling, and hole formation while samples were being collected. It is speculated that the temperatures reached during the tests $\left(<300^{\circ} \mathrm{C}\right)$, were not severe enough to destabilize the polycarbonate matrix and gasify its components. Polycarbonate glass transition (softening) temperature is between $145^{\circ} \mathrm{C}$ and $150^{\circ} \mathrm{C}$ [21], and melting temperature between $215^{\circ} \mathrm{C}$ and $338^{\circ} \mathrm{C}$ [22, 35]. During the most severe tests conducted, the specimens began to soften to the point of losing structural integrity. At high temperatures, polycarbonate tends to oxidize as a prelude to thermal degradation, producing gaseous products such as $\mathrm{CO}_{2}, \mathrm{O}_{2}$ and $\mathrm{H}_{2} \mathrm{O}$ (among others). These gasses were not explicitly detected in the current experimental scheme. However, by extracting the ions for nitrogen, oxygen and water, some insights can be drawn. For example, the air supplied to the facepiece for breathing was dried, such that presence of elevated concentrations of water might suggest that the polycarbonate is undergoing an oxidation process [36]. Therefore, it is possible that even though components of polycarbonate (and other polymers present in the facepiece lens) were not off gassing, it was reacting with air at high enough temperatures that resulted in an oxidation process. 
Cross-sectional analysis of the facepieces provided evidence that thermal damage, at least up until hole formation, did not penetrate uniformly through the thickness of the lens (Figure 21). As bubbles formed and damage accumulated during the radiant exposure to the outside of the facepiece, the air entering the facepiece cooled the interior surface such that bubble accumulation and pathway for damage was concentrated on the outer surface of the facepiece lens (Figure 21). Discoloration of the lens that occurred due to polymer oxidation in some tests is also limited to the outer surface of the lens (Figure 22). Thus, products of degradation that may be released in other formulations are likely to initiate outside the breathing zone.
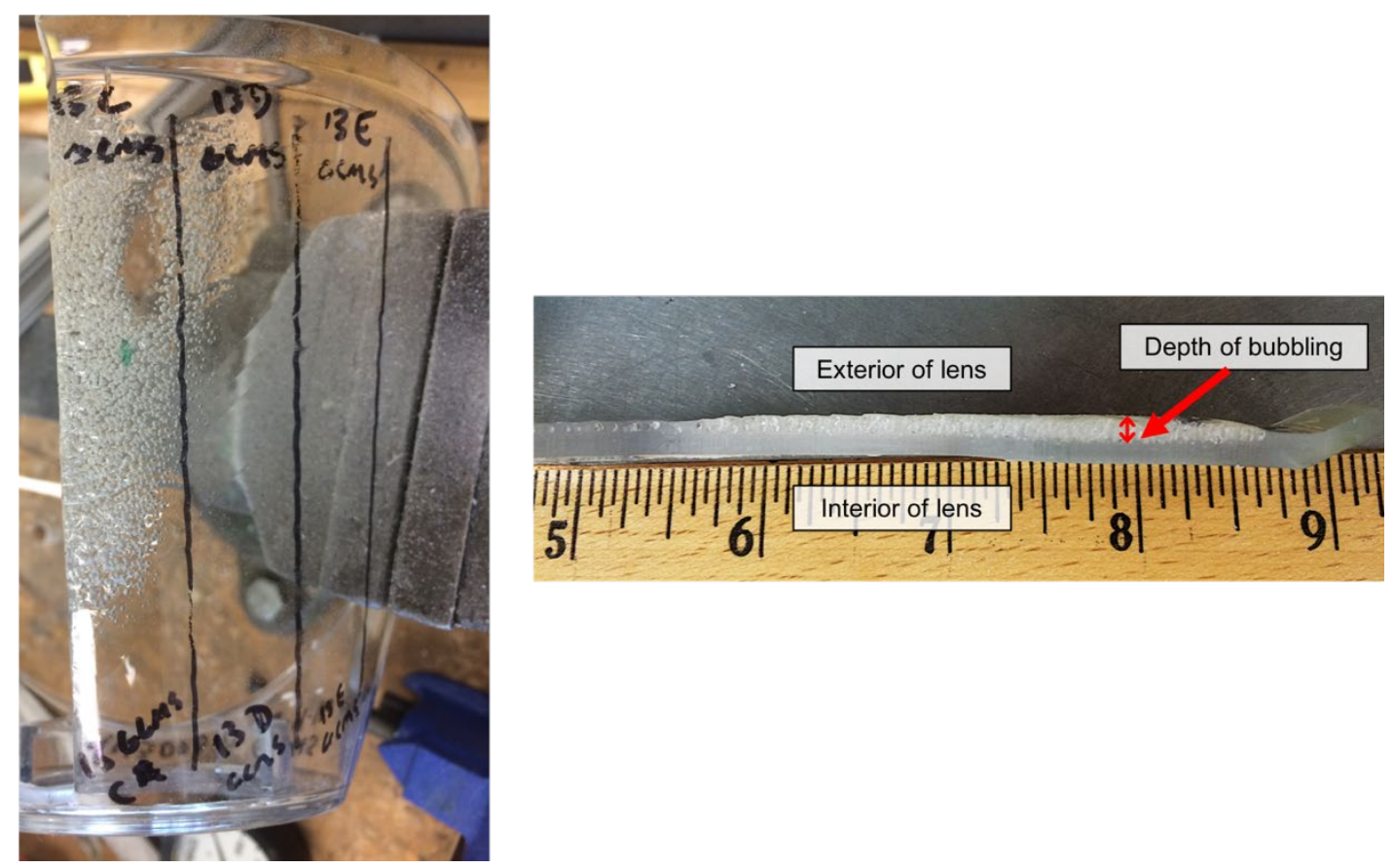

Figure 21. Damaged facepiece and cross-section showing damage only to exterior of facepiece. 


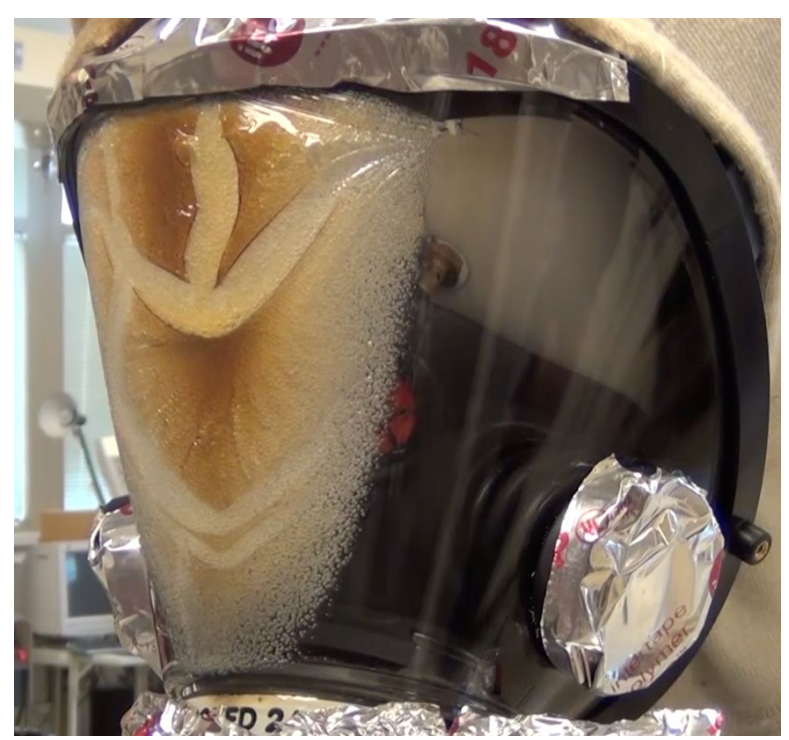

Figure 22. Facepiece lens showing discoloration as a result of polymer oxidation.

\section{Liquid Sample Injections}

The tests involving liquid injections of the dissolved lens materials in chloroform indicated that the key component of the facepieces was bisphenol A (BPA) while some additional compounds were detected that are typically used for coatings of polycarbonate lenses. Attempts were made to match each peak in a TIC with a corresponding compound from NIST's 2014 mass spectral database [37] by comparing their respective mass spectrums. The peaks identified in this report were matched with a confidence higher than $90 \%$. An example mass spectrum for BPA is shown in Figure 23, compared to its counterpart in the NIST database [37].
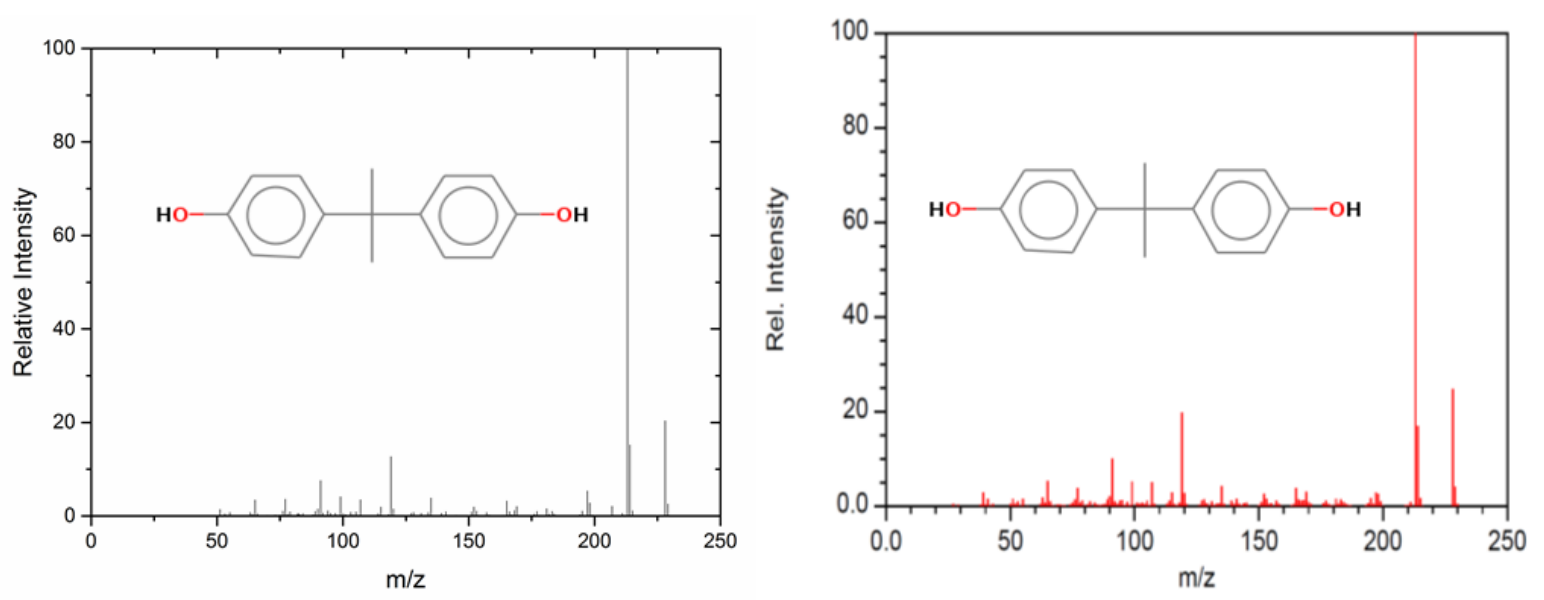

Figure 23. Mass Spectrum of BPA from current experiments (left) and from the NIST database [37] (right). 
The TIC results for the unexposed SCBA facepieces and polycarbonate sheet are shown in Figure 24, and the corresponding identified peaks are shown in Table 11. For the polycarbonate sample, the identified peaks were 4-(1-Methyl-1-phenylethyl)phenol, or more commonly known as 4-Cumylphenol and BPA. The observance of BPA is as expected. The observance of 4-Cumylphenol, here illustrates the end group, chain terminator, used to end the polymerization process [38]. Similar peaks for 4-Cumylphenol and BPA were observed for all unexposed facepiece materials. The relative concentrations of BPA vary in each of the samples, but are consistently present. Normally the solvent, in this case chloroform, is vented and does not reach the MS or are filtered out. Other compounds that were found include diphenyl carbonate, chlorobenzene, p-tert-Butylphenol and triphenylphosphine. Phenolic additives are sometimes used in polyurethane coatings, which could have been with the source for chlorobenzene [39]. P-tert-Butylphenol is used as an end group during the solvent method, to control the molecular weight of the polymers. Triphenylphosphine may be used in the copolymerization of BPA phenol derivatives of triphenylphosphine, in order to modify and enhance the fire resistance properties of the polycarbonate. While present in detectable abundance in the dissolved facepiece lens material, none of these chemicals were detected off gassing from the facepieces during high temperature exposures. 

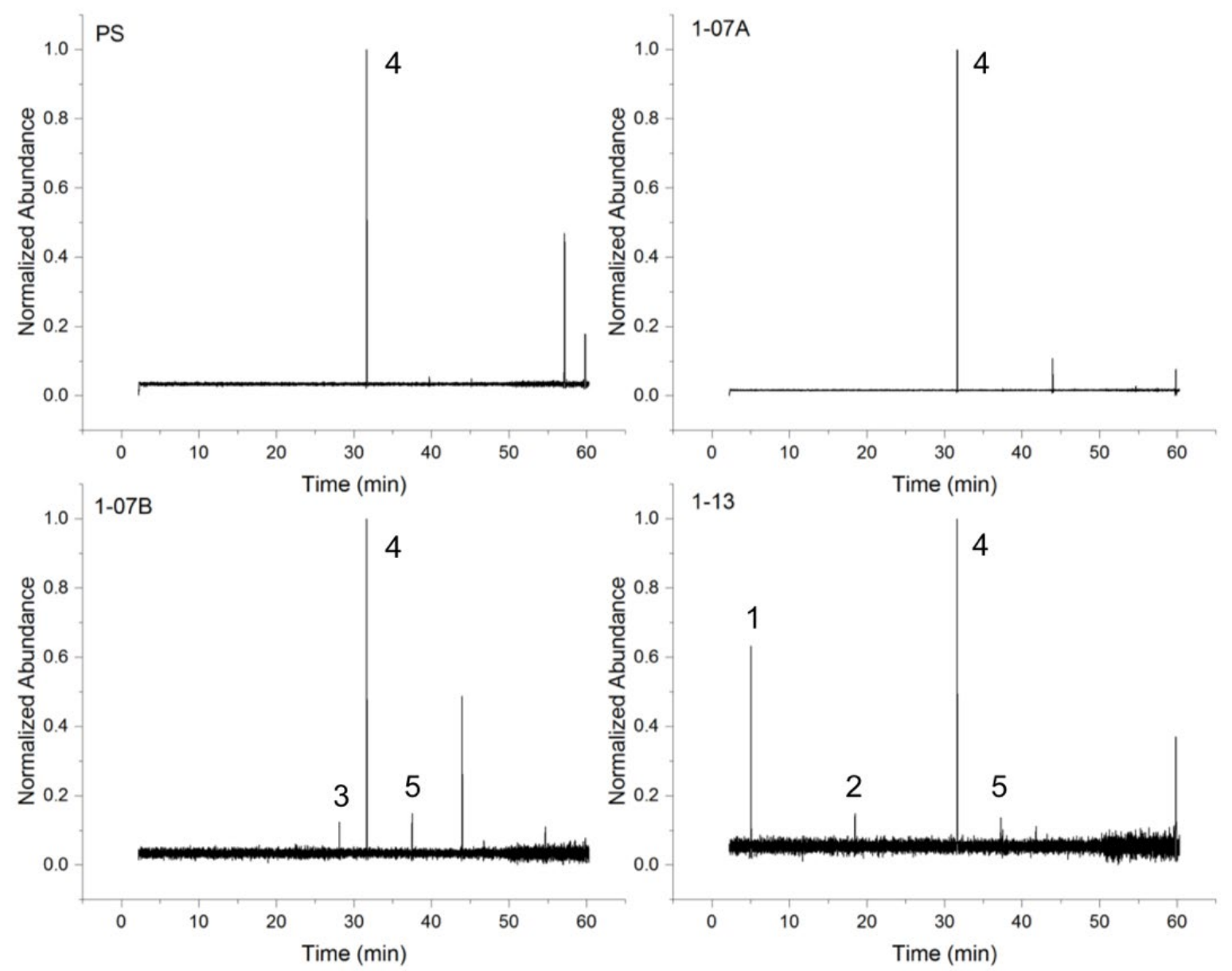

Figure 24. TIC graph for the chloroform dissolved liquid injections of SCBA facepiece samples and polycarbonate blanks without any heat exposure.

Table 11. Compounds identified from the TIC of the unexposed liquid injections.

\begin{tabular}{|c|c|c|c|}
\hline Compound & $\begin{array}{l}\text { Retention } \\
\text { Time (min) }\end{array}$ & Compound & Common Name \\
\hline 1 & 5.06 & Chlorobenzene & \\
\hline 2 & 18.47 & p-tert-Butylphenol & \\
\hline 3 & 28.20 & Diphenyl Carbonate & \\
\hline 4 & 31.66 & 4-(1-Methyl-1-phenylethyl)phenol & 4-Cumylphenol \\
\hline 5 & 37.53 & 4,4-(1-Methylethylidene)bis-phenol & Bisphenol A \\
\hline 6 & 43.96 & $\begin{array}{c}2((2 \mathrm{H} \text {-benzotriazol-2-yl)-4-(1,1,3,3,- } \\
\text { tetramethylbutyl))phenol }\end{array}$ & Octrizole \\
\hline
\end{tabular}


In order to identify changes in material properties after thermal exposure, similar liquid injections were conducted after exposure to 'Emergency Situation' thermal conditions. TIC results for all the exposed 1-07B and 1-13 SCBA facepiece samples are compared to the unexposed TICs in Figure 25. In general, the results for the exposed facepieces, identified many of the same compounds as the unexposed samples as well as some new compounds, at longer elution times. Similar to the unexposed materials, the chain terminator 4-cumylphenol was observed in all samples. However, BPA concentration was reduced such that it was not identified in many samples or was below the detectable limits of the GCMS, possibly indicating that some sort of consumption reaction was undergone.

In general, yellow discoloration of the SCBA facepieces is likely attributed to the oxidation of the polycarbonate, and more specifically to the occurrence of ring oxidation of BPA [40]. It is important to note that polycarbonate tends to oxidize at an appreciable rate at temperatures of $250-300{ }^{\circ} \mathrm{C}$, and may form alkylperoxide radicals, followed by their isomerization in the formation of a number of oxygen-containing carbonyl groups, which may undergo further conversions [41]. Several cyclic compounds were noted in Figure 25, but not identified at a high enough level of confidence between the elution times of 40 and 60 minutes. The ratio between the concentration and signal strength to background is small, making it hard to correctly match with the NIST database. Additionally, and more probable, is that several different compounds were eluting at the same time, resulting in overlap between peaks. There are more unidentified compounds in the exposed samples, possibly a result of the thermal exposure fundamentally affecting the facepiece composition which results in reactions and the breaking of polymer bonds. Determination of the compounds produced during the facepiece degradation was outside the scope of the orinal project, and thus further research would be needed to draw definitive conclusions. 

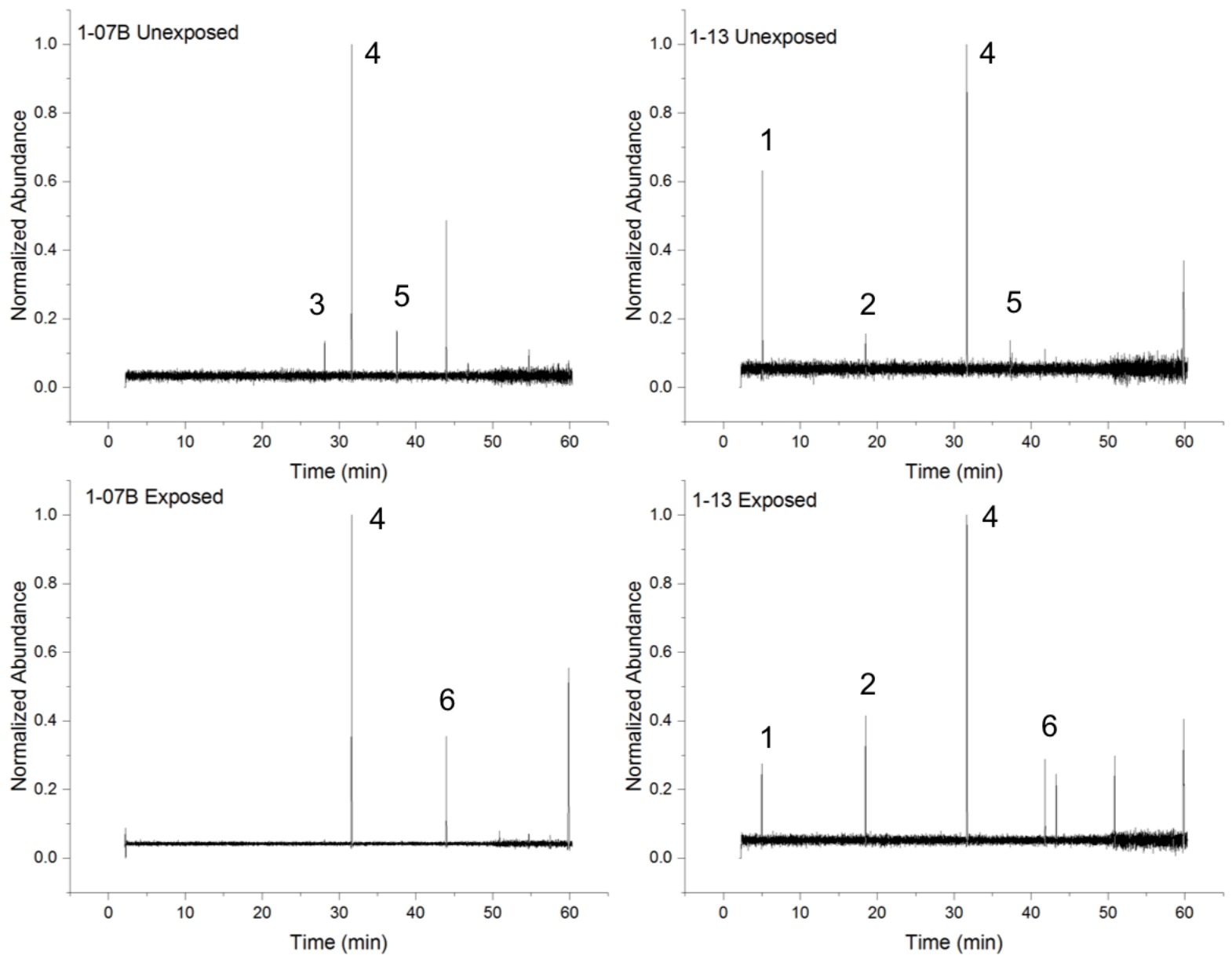

Figure 25. TIC graph for the chloroform dissolved liquid injections of SCBA facepiece samples and polycarbonate blanks with heat exposure.

Minimum Detection Limit

To determine the minimum detection limit for the gaseous injection of off-gassing from the facepiece lenses, $1 \mu \mathrm{l}$ of the liquid dissolved polycarbonate blank material was injected with $150 \mu \mathrm{l}$ of air at $138 \mathrm{kPa}(20 \mathrm{psi})$ through the valve gaseous injection system, in order to simulate the gaseous injection tests conducted with the breathing mannequin head. The total mass injected of polycarbonate was $20 \mu \mathrm{g}$ at $138 \mathrm{kPa}(20 \mathrm{psi})$, and when adjusted to atmospheric conditions would be $14.8 \mu \mathrm{g}$ of polycarbonate. The mass of injected air was $248 \mathrm{mg}$ at $138 \mathrm{kPa}(20 \mathrm{psi})$ and room temperature which is converted to $184 \mathrm{mg}$ at atmospheric pressure. Analysis of the TIC revealed that the 4-cumylphenol and BPA peaks account for approximately $8 \%$ of the mass when compared to that of air. This result is consistent with the amount of mass injected in the system, which results in a mass ratio of $8.1 \%$ of SCBA facepiece to air. An acceptable ratio for determining a peak with $99 \%$ accuracy is that the signal is at least three times as much as the deviation from the background signal. Based on this analysis we can reasonably predict that the current setup 
under $101 \mathrm{kPA}(1 \mathrm{~atm})$ would be able to detect polycarbonate if an injection sample had at least 35ng.

\section{Conclusions}

SCBA facepieces with similar geometry produced following both NFPA 1981 - 2007 Edition and the 2013 Edition, were exposed to a range of radiant heat conditions representative of the fire ground after which mechanical, thermal and chemical off-gas testing was performed. The NFPA 1981 - 2013 Edition facepieces had higher tensile strength and were able to absorb more energy, but failed in a more brittle fashion with minimal deformation before failure. Repeat exposure to moderate thermal loads $\left(5 \mathrm{~kW} / \mathrm{m}^{2}\right.$ for 5 minutes for 100 cycles) significantly affected the tensile strength and ductility of the 2007 edition facepiece to a larger extent than the 2013 edition facepiece. Interestingly, the dynamic mechanical properties in samples tested after this exposures were similar to unexposed samples. Exposures to higher thermal loads over shorter duration $\left(10 \mathrm{~kW} / \mathrm{m}^{2}\right.$ for 1.5 minutes for 10 cycles) did not result in significant differences in quasistatic mechanical properties relative to the unexposed lenses. However, there were notable reductions in maximum load and energy absorbed at this level of exposure for both facepieces during dynamic mechanical testing.

New and exposed facepieces from both editions of the NFPA 1981 standard were able to maintain positive pressure within the facepiece when exposed to the thermal conditions of the NFPA 1981 Lens Radiant Heat Test. However, important damage evolution differences were noted between facepiece models. The more rapid time to bubbling in the $2007 \mathrm{vs}$ 2013 edition facepieces (0:59-1:17 vs. 2:10-2:24, m:ss) was noteworthy as bubbling significantly reduces the firefighters vision and may impact emergency egress. Further, 2013 edition lenses did not reach hole formation in any condition, but holes formed in the 2007 edition lenses between 2:28 (m:ss) and 3:03 depending on the pre-test thermal exposure. For exposed facepieces, there were minimal differences in time to damage event (microcracking, bubbling, pulsation, and hole formation), though damage evolved more rapidly in the 2007 edition facepiece after $10 \mathrm{~kW} / \mathrm{m}^{2}$ exposure.

The off-gassing experiments allowed collection of gasses in the facepiece airspace at conditions relevant to those encountered on the fireground under both 'Ordinary' and 'Emergency' conditions. No significant off-gassing of polymeric materials was observed at those conditions using the GC-MS apparatus employed for this study. An unusually high concentration of water was observed outside of the lens, which could indicate that the polycarbonate is undergoing an oxidation process that preludes thermal degradation. SCBA facepiece samples were dissolved in chloroform and injected in liquid form into the GC-MS wherein thethe common monomer of BPA and the chain terminator 4Cumylphenol along with other end groups, and in some cases, phenolic additives used in 
coatings were identified. Several suspected oxidation products were also detected in the exposed facepieces but not in the unexposed material, which supports the theory that rather than the polycarbonate off gassing, it reacts under high temperatures with the ample oxygen around it to produce oxidation products. Furthemore, cross sectioning the facepiece to visualize damage suggests that products produced during facepiece bubbling are likely isolated to the exterior of the lens and do not appear to pose a risk for inhalation by the firefighter wearing the facepiece.

\section{References}

1. National Fallen Firefighters Foundation, 2015 National Fire Service Research Agenda. 2016.

2. National Fallen Firefighters Foundation, Report of the 2nd National Fire Service Research Agenda Symposium. 2011.

3. Mensch, A. and N. Bryner, Emergency First Responder Respirator Thermal Characteristics Workshop Proceedings, in NIST Special Publication 1123. National Institute of Standards and Technology: Gaithersburg, MD.

4. National Fire Protection Association, NFPA Safety Alert: Self-Contained Breathing Apparatus, in NFPA Safety Alert: Self-Contained Breathing Apparatus. 2012.

5. National Institute of Occupational Health and Safety - Fire Fighter Fatality Investigation and Prevention Program, Career Lieutenant and Fire Fighter Die in a Flashover During a Live-Fire Training Evolution - Florida. 2003.

6. National Institute of Occupational Health and Safety - Fire Fighter Fatality Investigation and Prevention Program, Career Officer Injured During a Live Fire Evolution at a Training Academy Dies Two Days Later - Pennsylvania. 2007.

7. National Institute of Occupational Health and Safety - Fire Fighter Fatality Investigation and Prevention Program, Career Fire Fighter Dies in Wind Driven Residential Structure Fire - Virginia. 2008.

8. National Institute of Occupational Health and Safety - Fire Fighter Fatality Investigation and Prevention Program, Volunteer Fire Fighter Dies While Lost in Residential Structure Fire - Alabama. 2009.

9. National Institute of Occupational Health and Safety - Fire Fighter Fatality Investigation and Prevention Program, A Volunteer Mutual Aid Captain and Fire Fighter Die in a Remodeled Residential Structure Fire - Texas. 2008.

10. National Institute of Occupational Health and Safety - Fire Fighter Fatality Investigation and Prevention Program, Career Probationary Fire Fighter and Captain Die As a Result of Rapid Fire Progression in a Wind-Driven Residential Structure Fire - Texas. 2010.

11. Madrzykowski, D. Fatal Training Fires: Fire Analysis for the Fire Service. in International Interflam Conference. 2007. London, England.

12. National Fire Fighter Near Miss Reporting System, Engine Crew Surprised by Sofa Flare Up. 2006.

13. National Fire Fighter Near Miss Reporting System, Firefighter Experiences Near Miss in Flashover Trailer Training. 2006. 
14. National Fire Fighter Near Miss Reporting System, Facepiece Damaged During Live Burn Training. 2007.

15. National Fire Fighter Near Miss Reporting System, Problem With CAFS Unit Identified at Live Burn. 2008.

16. Krishnan, A.V., P. Stathis, S.F. Permuth, L. Tokes, and D. Feldman, Bisphenol-A: an estrogenic substance is released from polycarbonate flasks during autoclaving. Endocrinology, 1993. 132(6): p. 2279-86.

17. Vogel, S.A., The politics of plastics: the making and unmaking of bisphenol a "safety". Am J Public Health, 2009. 99 Suppl 3: p. S559-66.

18. Melzer, D., N.E. Rice, C. Lewis, W.E. Henley, and T.S. Galloway, Association of urinary bisphenol a concentration with heart disease: evidence from NHANES 2003/06. PLoS One, 2010. 5(1): p. e8673.

19. Li, D.-k., Z.-j. Zhou, M.-h. Miao, Y.-h. He, J.-t. Wang, J. Ferber, L.J. Herrinton, E.-S. Gao, and W. Yuan, Urine Bisphenol-a (BPA) Level in Relation to Semen Quality and Sexual Dysfunction. Epidemiology, 2011. 22(1): p. S79-S80.

20. Sugiura-Ogasawara, M., Y. Ozaki, S. Sonta, T. Makino, and K. Suzumori, Exposure to bisphenol $A$ is associated with recurrent miscarriage. Hum Reprod, 2005. 20(8): p. 2325-9.

21. Hirschler, M., Thermal Decomposition of Polymers, in SFPE Handbook of Fire Protection Engineering, P.J. DiNenno, Editor. 2008, National Fire Protection Association: Quincy, MA. p. 112-143.

22. Schultz, A., PVT, Specific Heat, and Thermal Transitions, in Handbook of Polycarbonate Science and Technology. 2000, Marcel Dekker, Inc: New York, NY. p. 149-178.

23. Alarie, Y.C. and R.C. Anderson, Toxicologic and acute lethal hazard evaluation of thermal decomposition products of synthetic and natural polymers. Toxicology and Applied Pharmacology, 1979. 51(2): p. 341-362.

24. Volunteer Fire Fighter Found Unresponsive With His Facepiece Off Dies Eight Days Later - Maryland, \# F2013-13. 2014, National Institute for Occupational Safety and Health: Morgantown, WV.

25. A Career Captain Dies and 9 Fire Fighters injured in a Multistory Medical Building Fire-North Carolina, F2011-18. 2012, National Institute for Occupational Safety and Health.

26. Donnelly, M.K., W.D. Davis, J.R. Lawson, and M.J. Selepak, Thermal Environment for Electronic Equipment Used by First Responders, NIST TN 1474. 2006, National Institute of Standards and Technology: Gaithersburg, MD.

27. Madrzykowski, D., Fire Fighter Equipment Operational Environment: Evaluation of Thermal Conditions, FPRF-2017-05. 2017, Fire Protection Research Foundation: Quincy, MA 02169.

28. Utech, H. Status Report on Research Programs for Firefighters Protective Clothing. in 45th Annual Fire Department Instructors Conference Proceedings. 1973. International Society of Fire Service Instructors.

29. Putorti, A., A. Mensch, N. Bryner, and G. Braga, Thermal Performance of SelfContained Breathing Apparatus Facepiece Lenses Exposed to Radiant Heat Flux, NIST TN 1785. 2013, National Institute of Standards and Technology: Gaithersburg, MD. 
30. Horn, G.P., R.M. Kesler, J.W. Regan, and D. Madrzykowski, A Study on the Effect of Repeat Moderate Intensity Radiant Exposures on SCBA Facepiece Properties, NIST GCR 17-014. 2017, National Institute of Standards and Technology: Gaithersburg, MD.

31. Chou, B.R., S.J. Dain, and B.B. Cheng, Effect of Ultraviolet Exposure on Impact Resistance of Ophthalmic Lenses. Optom Vis Sci, 2015. 92(12): p. 1154-60.

32. National Fire Protection Association, NFPA 1981: Standard on Open-Circuit Self-Contained Breathing Apparatus (SCBA) for Emergency Services. 2013, National Fire Protection Association: Quincy, MA.

33. ASTM International, Standard Test Method for Tensile Properties of Plastics. 2010: West Conshohocken, PA.

34. ASTM International, Standard Test Method for Compressive Residual Strength Properties of Damaged Polymer Matrix Composite Plates. 2017: West Conshohocken, PA.

35. Krasny, J., J.A. Rockett, and D. Huang, Protecting fire fighters exposed in room fires: Comparison of results of bench scale test for thermal protection and conditions during room flashover. Fire Technology, 1988. 24(1): p. 5-19.

36. Lee, L.-H., Mechanisms of thermal degradation of phenolic condensation polymers. I. Studies on the thermal stability of polycarbonate. Journal of Polymer Science Part A: General Papers, 1964. 2(6): p. 2859-2873.

37. NIST/EPA/NIH Mass Spectral Library, U.S.o. Commerce, Editor. 2014: Gaithersburg, Maryland.

38. Ito, Y., H. Ogasawara, Y. Ishida, H. Ohtani, and S. Tsuge, Characterization of End Groups in Polycarbonates by Reactive Pyrolysis-Gas Chromatography. Polymer Journal, 1996. 28: p. 1090.

39. Yokoyama, N., Properties of polyurethane coatings containing additives of phenolic compounds. Journal of Applied Polymer Science, 2006. 102(3): p. 20992106.

40. Alin, J. and M. Hakkarainen, Migration from polycarbonate packaging to food simulants during microwave heating. Polymer Degradation and Stability, 2012. 97(8): p. 1387-1395.

41. Factor, A., W.V. Ligon, and R.J. May, The role of oxygen in the photoaging of bisphenol A polycarbonate. 2. GC/GC/high-resolution MS analysis of Floridaweathered polycarbonate. Macromolecules, 1987. 20(10): p. 2461-2468. 